\title{
Investigation of negative cloud radiative forcing over the Indian subcontinent and adjacent oceans during the summer monsoon
}

\section{season}

\author{
B. V. Thampi ${ }^{1{ }^{*}}$ and R. Roca ${ }^{2}$ \\ ${ }^{1}$ Laboratoire de Météorologie Dynamique, UMR8539, UPMC, BP99, 4 place Jussieu, 75252 Paris, France \\ ${ }^{2}$ Laboratoire d'Etudes en Géophysique et Océanographie Spatiales, UMR5566, OMP, 14 Avenue E. Belin, \\ 31400 Toulouse, France \\ "now at: Science Systems and Applications, Inc. (SSAI), Hampton, VA, USA
}

Correspondence to: B. V. Thampi (btlmd@1md.jussieu.fr)

Received: 15 August 2013 - Published in Atmos. Chem. Phys. Discuss.: 6 November 2013

Revised: 14 March 2014 - Accepted: 7 April 2014 - Published: 3 July 2014

\begin{abstract}
Radiative properties of clouds over the Indian subcontinent and nearby oceanic regions $\left(0-25^{\circ} \mathrm{N}, 60-100^{\circ} \mathrm{E}\right)$ during the Asian summer monsoon season (June-September) are investigated using the Clouds and Earth's Radiant Energy System (CERES) top-of-the-atmosphere (TOA) flux data. Using multiyear satellite data, the net cloud radiative forcing (NETCRF) at the TOA over the Indian region during the Asian monsoon season is examined. The seasonal mean NETCRF is found to be negative (with its magnitude exceeding $\sim 30 \mathrm{Wm}^{-2}$ ) over (1) the northern Bay of Bengal (close to the Myanmar-Thailand coast), (2) the Western Ghats and (3) the coastal regions of Myanmar. Such strong negative NETCRF values observed over the Indian monsoon region contradict the assumption that near cancellation between LWCRF and SWCRF is a generic property of all tropical convective regions. The seasonal mean cloud amount (high and upper middle) and corresponding cloud optical depth observed over the three regions show relatively large values compared to the rest of the Indian monsoon region. Using satellite-derived cloud data, a statistical cloud vertical model delineating the cloud cover and single-scattering albedo was developed for the three negative NETCRF regions. The shortwave (SW), longwave (LW) and net cloud radiative forcing over the three negative NETCRF regions are calculated using the rapid radiative transfer model (RRTM) with the cloud vertical model as input. The NETCRF estimated from CERES observations show good comparison with that computed using RRTM (within the uncertainty limit of CERES observations). Sensitivity tests are conducted us-
\end{abstract}

ing RRTM to identify the parameters that control the negative NETCRF observed over these regions during the summer monsoon season. Increase in atmospheric water vapor content during the summer monsoon season is found to influence the negative NETCRF values observed over the region.

\section{Introduction}

Radiation at the top of the atmosphere and surface of Earth are significantly modulated by the presence of clouds in the atmosphere. Effect of clouds on the Earth's radiation budget can be gauged by cloud radiative forcing (CRF), which is defined as the difference between clear-sky and total-sky radiation (Charlock and Ramanathan, 1985). CRF can be estimated directly from satellite observation at the top of the atmosphere (TOA) (Ramanathan et al., 1989; Harrison et al., $1990)$ as well as at the surface by means of satellite inversion and modeling (Zhang et al., 1995; Rossow and Zhang, 1995; Pavlakis et al., 2008). Studies have shown that global average TOA shortwave cloud radiative forcing (SWCRF) is negative, while TOA longwave cloud radiative forcing (LWCRF) is positive, with the net effect being cooling of the Earthatmosphere system. However, over tropical convective regions, TOA LW and SW cloud radiative forcing are found to cancel each other (Ramanathan et al., 1989; Kiehl and Ramanathan, 1990; Kiehl, 1994; Hartmann et al., 2001; Futyan et al., 2004). Kiehl (1994) theorized that occurrence of cloud 
tops close to tropical tropopause over the western Pacific results in the observed near cancellation between the SW and LW CRF. Jensen et al. (1994) studied the sensitivity of TOA flux to cloud micro/macrophysical properties using a 1-D radiative transfer model and observed that net radiative forcing of cirrus near the tropical tropopause is positive for cloud optical depths less than $\sim 16$ and negative for larger optical depths. Studies show that changes in cloud particle size and optical depth can cause the net cloud radiative forcing (NETCRF) to vary between positive or negative values depending on the magnitude and direction of change (Zhang et al., 1999). Feedback of cloud radiative properties on the climate can be either positive or negative depending on the cloud microphysics and single-scattering properties (Liou and $\mathrm{Ou}, 1989$; Stephens et al., 1990).

There exist few convective regions over tropics where near cancellation of SW and LW CRF is not strictly followed (Pai and Rajeevan 1998; Rajeevan and Sreenivasan, 2000; Hartmann et al., 2001; Futyan et al., 2004; Balachandran and Rajeevan, 2007). Rajeevan and Sreenivasan (2000) showed (using ERBE data) that NETCRF is negative for a sizeable area over the Indian region during the summer monsoon season. Long-term studies show that the northern Bay of Bengal region during the summer monsoon season is characterized by a large amounts of high clouds with cloud-top altitude close to the tropical tropopause (Devasthale and Fueglistaler, 2010; Meenu et al., 2010). The region also experiences the highest integrated latent heat release observed over the planet during the Asian summer monsoon season (Zuluaga et al., 2010). Rajeevan and Srinivasan (2000) proposed that the presence of large amounts of optically thicker high-level clouds are the main reason behind the observed negative NETCRF over the Bay of Bengal. Balachandran and Rajeevan (2007) showed that NETCRF over the oceanic regions of the Indian monsoon region is strongly correlated with changes in highcloud amount, while over the land regions, both middle- and high-cloud amount variations make a substantial contribution. Patil and Yadav (2005) observed that NETCRF over the Asian monsoon region undergoes a year-to-year variability with a maximum magnitude in 1988 and minimum in 1987, indicating association between monsoon rainfall activity and CRF over the region. Roca et al. (2004) studied the influence of atmospheric water loading on the LW cloud radiative forcing over the Bay of Bengal using idealized radiative transfer computations, and showed that negative cloud radiative forcing is closely associated with increased atmospheric water vapor loading.

Earlier studies suggest that the negative NETCRF observed over the Indian region $\left(0-25^{\circ} \mathrm{N}, 60-100^{\circ} \mathrm{E}\right)$ during the Asian summer monsoon season is mainly influenced by the cloud macrophysical properties (cloud amount, cloud height) with little understanding of the impact of microphysical (cloud optical depth, particle size and habit) and environmental variables (water vapor, SST). A comprehensive study detailing the influence of these variables on NETCRF over the Indian region during the summer monsoon season is yet to be carried out. Objective of the present study is to understand the influence of these parameters on the observed negative NETCRF over the Indian region during the summer monsoon season. This paper delineates various negative NETCRF regimes observed over the Indian region during the summer monsoon season using the Clouds and Earth's Radiant Energy System (CERES) TOA flux data and examines the factors that control it. The influence of cloud micro/macrophysical properties and environmental variables on the cloud radiative forcing over the Indian region is analyzed using satellite observations and modeling. The paper is divided into following sections. Section 2 describes the data used in the estimation of CRF and error analysis. Section 3 examines the radiative transfer model used for the computation of TOA flux and different parameterization schemes. Section 4 examines the CERES observation of CRF over the Indian region. Section 5 describes the comparison of NETCRF from CERES and RRTM simulations and various sensitivity analyses performed. Section 6 and 7 summarizes the main results of the paper.

\section{Data and methodology}

\subsection{CERES TOA flux data}

The mean cloud radiative forcing over the Indian region during the summer monsoon season (June-September) of 20022005 was derived by analyzing the TOA flux data from the CERES Aqua SRBAVG-GEO (edition 2A) data set, which contains the monthly mean regional TOA total-sky and clearsky radiative fluxes (LW and SW) in a $1^{\circ} \times 1^{\circ}$ latitudelongitude grid. CERES SRBAVG-GEO data use narrowband radiance from geostationary meteorological satellites to account for changes in flux and cloud conditions between daily CERES observations, which reduce temporal sampling errors. The uncertainties in the estimated CERES TOA flux are relatively small compared to that derived from the ERBE data (Loeb et al., 2005), mainly due to better scene identification and incorporation of better angular distribution models (Smith et al., 2012). CERES SRBAVG clear-sky monthly mean TOA fluxes are derived from CERES Single Scanner Footprint (SSF) data that are completely cloud-free according to $1 \mathrm{~km}$ resolution Moderate Resolution Imaging Spectroradiometer (MODIS) data. However, due to the coarse spatial resolution of the CERES instrument ( $20 \mathrm{~km}$ at nadir), estimation of clear-sky flux is possible only from geographical regions where clouds occur less frequently and cloudfree regions have a relatively large area. Because of this, clear-sky flux maps from CERES SRBAVG-GEO contain many gaps (no clear-sky flux data), especially over the Indian monsoon region. In order to circumvent this problem, TOA clear-sky flux data from the CERES Terra Energy Balanced and Filled (EBAF) edition 1A product (Loeb et al., 
2009a) were used in the present study. CERES EBAF data provide TOA clear-sky fluxes for many overcast regions that have no CERES clear-sky observations over the course of a month. CERES SSF TOA clear-sky fluxes require $99 \%$ of MODIS pixels (with $1 \mathrm{~km}$ nominal area) within the CERES footprint ( $20 \mathrm{~km}$ nominal) to be classified as clear. However, in a overcast cloudy region, there may be a $1 \mathrm{~km}$ clear-sky patch present inside a $20 \mathrm{~km}$ footprint region. The CERES EBAF product uses this clear-sky MODIS pixel radiance to derive broadband radiances, which are constrained to the overall CERES footprint to derive the TOA clear-sky flux. In the present study, monthly mean TOA total-sky flux from CERES SRBAVG-GEO product and monthly mean TOA clear-sky flux from the CERES EBAF product are used in the estimation of cloud radiative forcing over the Indian region during the summer monsoon season. More details regarding the CERES EBAF data set are available online (http: //ceres.larc.nasa.gov/products.php?product=EBAF-TOA).

CRF is used as a metric to assess the radiative impact of clouds on the climate system, which is defined as the difference between TOA clear- and total-sky flux. Using the CERES TOA flux measurements, the cloud radiative forcing is calculated by taking the difference between TOA clear-sky and total-sky flux:

$$
\mathrm{SWCRF}=\mathrm{SW}_{\text {clear }}-\mathrm{SW}_{\text {total }},
$$

$\mathrm{LWCRF}=\mathrm{LW}_{\text {clear }}-\mathrm{LW}_{\text {total }}$,

where the subscripts "clear" and "total" represent the TOA clear-sky and total-sky fluxes, respectively. The net cloud radiative forcing (NETCRF) at the TOA is estimated by adding the shortwave and longwave cloud forcing:

$\mathrm{NETCRF}=\mathrm{SWCRF}+\mathrm{LWCRF}$,

which can be re written as

$\mathrm{NETCRF}=\mathrm{SW}_{\text {clear }}+\mathrm{LW}_{\text {clear }}-\left(\mathrm{SW}_{\text {total }}+\mathrm{LW}_{\text {total }}\right)$.

To determine the cloud radiative forcing over the Indian region, the monthly mean TOA total-sky flux from CERES SRBAVG-GEO and the clear-sky flux from the CERES EBAF data set during the summer monsoon season (JuneSeptember) of 2002-2005 are used.

\subsection{Uncertainty analysis}

This section presents the methodology used to compute the total uncertainty in CERES TOA NETCRF due to uncertainties in the CERES TOA flux. Uncertainties in the CERES flux measurement can be broadly categorized into three main components: sampling errors, calibration errors and algorithm errors. Sampling error refers to error associated with time sampling and spatial averaging of the data associated with the instrument normalization (Young et al., 1998), which corresponds to $0.3 \mathrm{Wm}^{-2}$ for the SW and LW flux
(Loeb et al., 2009a). An additional error term equal to the standard error of the regional mean TOA flux is also added to the sampling error term. The term "algorithm error" refers to the errors associated with data retrieval, which in this case mainly stems from uncertainties associated with narrow-tobroadband conversion of radiance, angular distribution models (ADM) and scene identification, whereas calibration error refers to the instrument measurement error (level 1 product error). More details regarding the of CERES TOA flux estimation and associated uncertainties can be found in Loeb et al. (2009a) as well as in the CERES EBAF data quality summary document. In the present analysis, it is assumed that sampling, calibration and algorithm errors associated with the CERES TOA flux are uncorrelated and independent. The total uncertainty in the TOA flux due to these different error sources can be expressed as (Chambon et al., 2013)

$$
\delta_{\text {TOAFLUX }}=\sqrt{\delta_{\text {sampling }}^{2}+\delta_{\text {calibration }}^{2}+\delta_{\text {algorithm }}^{2}} .
$$

Using the above equation, uncertainty in the CERES TOA clear- and total-sky flux (LW and SW) is estimated. The uncertainty computations are performed at the monthly mean scale using error estimates for a $1^{\circ} \times 1^{\circ}$ latitude-longitude grid area.

In order to estimate the uncertainty in NETCRF, the effect of propagation of variable uncertainty on the uncertainty of a function is to be considered. From Eq. (4), it can be seen that NETCRF is a function of SW and LW flux. Hence total uncertainty associated with the CERES NETCRF measurement is related to uncertainties in CERES SW and LW flux (Loeb et al., 2009b). Using the general law of error propagation, it is possible to analytically determine how measurement uncertainty propagates into quantities, which are functions of the measurement. For a multivariable function $y\left(x_{1}, x_{2}, x_{3}, \ldots x_{N}\right)$, the total uncertainty in $y$ due to uncertainty in the input variables $x$ (assuming that error contributions are small compared to the absolute value of the variable) can be expressed as (Taylor, 1982; Lo, 2005)

$$
\delta y=\sqrt{\sum_{i=1}^{N}\left(\delta x \frac{\partial y}{\partial x_{i}}\right)^{2}+\sum_{i \neq j=1}^{N}\left(R_{i j} \delta x_{i} \delta x_{j} \frac{\partial y}{\partial x_{i}} \frac{\partial y}{\partial x_{j}}\right)},
$$

where $\delta y$ is the total uncertainty in $y, \delta x_{i}$ and $\delta x_{j}$ are the uncertainties associated with the input variables $\left(x_{i}\right.$ and $\left.x_{j}\right)$, and $R_{i j}$ represents the correlation coefficient between the input variables. The uncertainty in $y$ is governed by the (a) change in $y$ for a given change in the variables $x_{i}$ and $x_{j}$ (partial derivatives), (b) uncertainties in the input variable $\delta x_{i}$ and $\delta x_{j}$, and (c) how the variables $x_{i}$ and $x_{j}$ are correlated. If $x_{i}$ and $x_{j}$ are not correlated and independent of each other, the second term in Eq. (6) vanishes and the equation takes the form of a Gaussian error propagation formula (Taylor, 1982; Evans et al., 1984). Depending on the correlation between individual input variables and sign of the product of partial derivatives in the second term of Eq. (6), uncertainty in $y$ can 
increase or decrease. The uncertainties in the CERES TOA SW and LW (clear- and total-sky) flux represent the input variables in the Eq. (6), and $R$ represents the correlation between these two variables. However, if TOA flux from two different data sets are used for computing the NETCRF (e.g., total-sky flux from CERES and clear-sky flux from ECMWF reanalysis), the input fluxes will not be correlated and the second term in Eq. (6) will vanish. In the present analysis, uncertainty in the CERES TOA SW and LW flux (using Eq. 5) as well as the correlation coefficient between the fluxes are computed. Using these values as input in Eq. (6), the total uncertainty in the NETCRF is estimated.

\subsection{Cloud data}

The seasonal mean cloud parameters from the CERES SRBAVG2-GEO data set for the summer monsoon season of 2002-2005 are used in the study. The SRBAVG2-GEO cloud data include layer-averaged monthly mean cloud and aerosol retrievals from MODIS and geostationary satellites (Remer et al., 2005; Menzel et al., 2008). The MODISderived cloud fraction and cloud optical depth are believed to be more accurate than that from geostationary satellites owing to the higher quality of the MODIS data. Studies show that MODIS could detect (over tropics) cirrus clouds of cloud optical depth as low as 0.02 with an uncertainty factor of 2 (Dessler and Yang, 2003). However, combining geostationary satellite data measurements with the CERESMODIS data minimizes the temporal sampling errors and incorporates the diurnal variation in cloud amount and TOA flux between the two daily MODIS Aqua measurements. The SRBAVG2-GEO cloud data provide information about retrieved cloud parameters in four atmospheric layers that are a combination of MODIS- and geostationary-derived cloud retrievals. Seasonal mean values of cloud fraction, cloudtop height, cloud particle size and cloud optical depth available from the SRBAVG-GEO cloud database for high (cloudtop pressure $h<300 \mathrm{hPa}$ ), upper-middle ( $h=300-500 \mathrm{hPa}$ ), lower-middle ( $h=500-700 \mathrm{hPa})$ and low-level $(h>700 \mathrm{hPa})$ clouds, respectively, are used in the analysis.

\subsection{ISCCP-FD TOA flux data}

The International Satellite Cloud Climatology Project (ISCCP) data comprise an archive of more than 20 years of global cloud observations. ISCCP data utilize the radiance information from a series of geostationary satellites to create 3-hourly global maps of cloudiness. The ISCCP-FD data are an improved version of a previous ISCCP radiative flux product (Zhang et al., 1995) and provide radiative fluxes at the TOA, surface and several levels within the atmosphere (Zhang et al., 2004). ISCCP-FD data provide global totalsky and clear-sky fluxes (at surface, $680 \mathrm{mbar}, 440 \mathrm{mbar}$, $100 \mathrm{mbar}$ and TOA) for every $3 \mathrm{~h}$ interval in the shortwave and longwave range. Intercomparison of monthly mean fluxes from ISCCP-FD with ERBE and CERES suggests that there exists an uncertainty on the order of $\sim 5-10 \mathrm{Wm}^{-2}$ in the calculated TOA flux from the ISCCP-FD data set. Details regarding the data and methodology adopted in the estimation of ISCCP-FD flux are provided in Zhang et al. (2004) and Rossow et al. (2005). In the present study, TOA SW and LW fluxes from the ISCCP radiative flux data set (ISCCPFD) for the June-September months of 2002-2005 are used to estimate the seasonal mean CRF over the Indian region.

\section{Rapid radiative transfer model}

The rapid radiative transfer model (RRTM) is a band model for the calculation of longwave and shortwave atmospheric radiative fluxes and heating rates (Mlawer et al., 1997; Iacono et al., 2000; Clough et al., 2005). RRTM uses the correlated-k method, which is an accurate and computationally fast radiative transfer scheme. TOA LW fluxes calculated by RRTM agree with those computed by line-by-line radiative transfer model within $\sim 1 \mathrm{Wm}^{-2}$ range, while $S W$ fluxes agree within $\sim 1.5 \mathrm{Wm}^{-2}$ range (Clough et al., 2005; Morcrette et al., 2008). During the Spectral Radiance Experiment (SPECTRE), results from the RRTM flux simulations are validated against other radiation models for various atmospheric conditions (tropical, mid-latitude summer/winter) (Ellingson and Fouquart, 1991; Ellingson and Wiscombe, 1996). An important feature of RRTM is that it incorporates Monte Carlo independent column approximation (McICA) to represent sub-grid cloud variability (Barker et al., 2003; Pincus et al., 2003). A 1-D column version of RRTMG is used in the present study to compute the TOA fluxes. RRTM input data typically consist of surface emissivity, cloud/aerosol optical depth; altitude profiles (60 atmospheric pressure levels) of temperature, pressure, cloud fraction and single-scattering albedo; atmospheric mixing ratio profiles of water vapor, ozone, $\mathrm{CO}_{2}$, methane and other trace gases; etc.

In the present study, a tropical model atmosphere incorporating the above-mentioned parameters is used as input in RRTM simulations. An idealized altitude profile of atmospheric water vapor mixing ratio is built and used in the model simulations. For this purpose, an altitude profile of relative humidity $(\mathrm{RH})$ in the atmosphere is constructed following the methodology adopted in Roca et al. (2004). In order to construct the vertical profile, first it is assumed that the relative humidity is constant in the atmospheric boundary layer (between surface and to $850 \mathrm{hPa}$ ) and in the stratospheric layers $(<100 \mathrm{hPa})$. An RH value of $85 \%$ is assumed for the boundary layer and $10 \%$ for the stratospheric layer in all the profiles. The free-tropospheric (between 850 and $100 \mathrm{hPa}$ ) humidity is then varied from 5 to $100 \%$ in steps of 5 to create a number of $\mathrm{RH}$ altitude profiles. By converting the relative humidity to corresponding water vapor mixing ratio, a number of idealized water vapor mixing ratio profiles are created. The precipitable water (PW) concentration for 
each profile is estimated by integrating the water vapor mixing ratio from the surface to the top of the model atmospheric layer. In the present model simulations, changing the freetropospheric humidity (from 5 to $100 \%$ ) in the model atmospheric profile leads to a corresponding change in the PW from 33 to $68 \mathrm{~mm}$.

Using RRTM, TOA flux is estimated for every half-hour interval for a full day, which is then integrated to obtain the daily mean TOA SW and LW flux. The total-sky SW and LW fluxes are estimated by incorporating cloud parameters (cloud cover, optical depth and single-scattering albedo) into the model computation, whereas clear-sky flux estimation does not include any cloud data. In the computation of total-sky LW flux using RRTM, an altitude profile of mean cloud cover and cloud optical depth (from CERES data) for the study region is used. For the total-sky SW flux computation, in addition to cloud cover and optical depth, an altitude profile of single-scattering albedo is also required (which is not available from the satellite measurements). In addition, the model also requires information regarding vertical overlap between different cloud layers. However, satellite-derived cloud cover data do not provide information about overlap among different cloud layers in the atmosphere, without which modeling of TOA flux is difficult. To circumvent this deficiency, parameterization schemes are used to determine the vertical overlap between different cloud layers and cloud single-scattering albedo (ice and water clouds). Details regarding the cloud overlap scheme and single-scattering albedo parameterizations are described in the subsequent sections.

\subsection{Parameterization schemes}

\subsubsection{Cloud overlap}

Modeling of radiative flux due to clouds is complicated by difficulties in parameterizing its single-scattering properties (Liou, 1986) and cloud vertical structure (Weare, 1999; Rossow et al., 2005). Satellite observations of multilayered clouds from space only provide information about the topmost cloud layer encountered with lower level clouds being either fully or partially observed. If there is no overlap among different cloud layers in an atmospheric column, then cloud amount at each level observed by the satellite is the actual cloud amount. However, this assumption does not hold true in most cases involving partially cloudy skies. When there is overlap among different cloud layers, information about the actual amount of cloud in the lower levels is not fully recorded by satellites. Even with enhanced satellite and surface observation capabilities, information about cloud vertical structure is rather limited. The presence of partially filled cloud layers in the atmosphere creates problems in the model computation of the radiative fluxes because of the nonlinear relation between cloud properties and TOA fluxes (Bergmann and Hendon, 1998). This, along with lack of in- formation about the vertical cloud overlap in the model, can lead to large errors in the estimated radiative fluxes. In order to circumvent this problem, most models employ cloud overlap schemes for computing the radiative fluxes (Collins, 2001; Zhang et al., 2004; Rossow et al., 2005; Cole et al., 2011). Cloud overlap schemes are also used by satellite simulators in comparing the simulated cloud data with observations from passive or active remote sensing instruments (Klein and Jakob, 1999; Webb et al., 2001; Zhang et al., 2005; Bodas-Salcedo et al., 2011). Most radiative transfer models use vertical cloud overlap schemes like maximum overlap, random overlap or a combination of maximum and random overlap between cloud layers. In the present study, a cloud vertical model is developed using a type of maximum/random cloud overlap scheme.

Geleyn and Hollingsworth (1979) theorized that if clouds appear in two adjacent atmospheric layers, such cloud layers are usually vertical parts of the same cloud and there should be maximum overlap between them. Maximum overlap between two cloud layers can be expressed mathematically as

$C_{\max }=\max \left(C_{n}, C_{n-1}\right)$,

where $C_{n}$ and $C_{n-1}$ represent the cloud fraction of two adjacent cloud layers and $C_{\max }$ represents total cloud amount due to the overlap of two cloud layers. The random overlap assumption holds true only when the cloud layers are separated by at least one clear-sky layer. The random cloud overlap scheme assumes that the cloudiness in any given cloud layer is independent of the cloudiness of other layer (Warren et al., 1985). The total cloud amount in a vertical column assuming random overlap between cloud layers can be expressed mathematically as (Stephens et al., 2004)

$C_{\text {total }}=1-\prod_{n=1}^{l}\left(1-C_{n}\right)$,

where $C_{\text {total }}$ is the total cloud amount and $C_{n}$ is cloud fraction for a given cloud layer $n$. Tian and Curry (1989) showed that clouds tend to follow the maximum overlap scheme for a small horizontal cloud area, whereas they follow the random overlap for a large horizontal area $\left(\geq 500 \mathrm{~km}^{2}\right)$. But in reality, there are no completely random or maximum cloud overlap occurrences in nature but rather specific combinations of cloud types associated with specific meteorological conditions (Hahn et al., 2001; Rossow et al., 2005). Whether observed from satellites or surface, there exists a specific overlap relationship among different cloud types for each meteorological situation. In the present study, we are trying to develop a cloud overlap scheme that represents the altitude structure of a convective cloud system characterized by contiguous cloud layers. Since contiguous cloud layers can be expected to possess a fairly high degree of vertical correlation, a combination of random and maximum overlap 


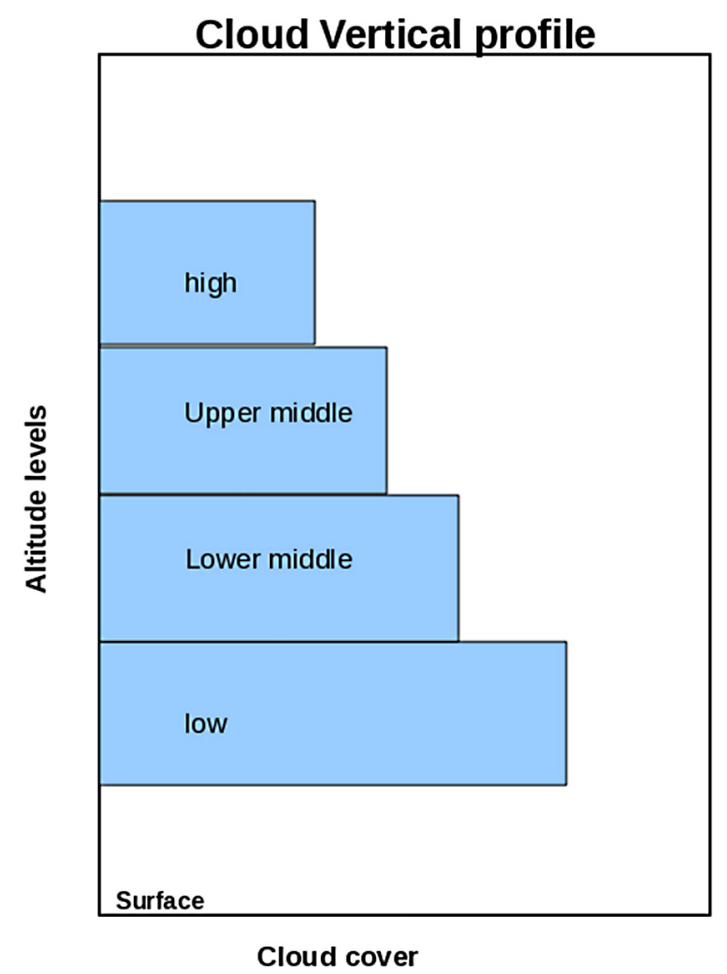

Figure 1. Schematic of a typical vertical distribution of cloud fraction. Each shaded block represents the effective cloud amount for the respective cloud group estimated using the cloud fraction data and cloud overlap (maximum/random) scheme.

schemes is used to represent the cloud vertical structure. Here it is assumed that cloud layers belonging to a particular cloud block (e.g., all the cloud layers in the high-cloud group) in a convective system are maximally overlapped, whereas adjacent cloud blocks are randomly overlapped (e.g., between high- and upper-middle cloud group). Therefore, effective cloud fraction for all the cloud layers belonging to a particular cloud block will remain the same (due to maximum overlap), whereas it will change from one cloud block to another (due to random overlap between two adjacent cloud blocks). Chou et al. (1998) also adopted a similar type of maximum/random assumption with maximum cloud overlap in each of the three cloud regions (lower, middle and upper troposphere) and random overlap between these cloud regions. Using this methodology (Eq. 7) and Eq. (8), an altitude profile of cloud cover is constructed using the cloud fraction data. A graphical representation of typical altitude structure of contiguous cloud layers calculated using the cloud overlap scheme is shown in Fig. 1.

The cloud vertical model is built as follows: the CERES SRBAVG-GEO layer-averaged cloud properties are defined mainly for four cloud groups - high-, upper-middle, lowermiddle and low-level clouds. The mean cloud-top pressure for each cloud group defines the boundary of cloud blocks in the model atmosphere; that is, cloud layers belonging to a high-cloud block in the model atmosphere are defined between the CERES mean high cloud-top pressure (usually between 180 and $250 \mathrm{hPa}$ in the model) and upper-middle cloud-top pressure (between 300 and $400 \mathrm{hPa}$ in the model). In the present cloud overlap scheme, the effective cloud fraction for all high-cloud layers in the model will be equivalent to the CERES high-cloud fraction since all cloud layers with in a particular cloud block are maximally overlapped. Effective cloud fraction for the upper-middle cloud block in the model is estimated assuming random overlap (using the Eq. 7) between the CERES high-cloud and uppermiddle-level cloud fraction. This newly estimated cloud fraction (using Eq. 8) is assigned to all the layers in the uppermiddle cloud block (maximum overlap) in the model atmosphere defined between the upper-middle cloud-top pressure and lower-middle cloud-top pressure. Using this methodology, effective cloud fraction for lower-middle and low-level clouds are also estimated. The base of the newly constructed cloud vertical profile is fixed at the top of boundary layer $(850 \mathrm{hPa})$, while the cloud top coincides with that of the highlevel cloud.

\subsubsection{Cloud single-scattering albedo (SSA)}

For estimating TOA SW flux using RRTM, altitude profile of cloud SSA is required along with cloud cover information. Single-scattering properties of clouds are governed by the cloud particle size, shape and water content. They also vary over a large range of values depending on the wavelength band under consideration. In this section, parameterization schemes used for deriving the single-scattering albedo (SSA) of ice and water clouds are explained. SSA parameterization provides a mathematical relationship between the cloud properties (particle size, optical depth, water content) and single-scattering albedo. Several attempts were made to parameterize the SSA of a cloud system solely based on the cloud water content alone (Sun and Shine, 1994; Platt, 1997). However, it was observed that cloud water content alone is insufficient and information about the cloud particle size is also required in the parameterization of SSA (Wyser and Yang, 1998). For water clouds, the single-scattering properties can be effectively parameterized either in terms of their average size (Slingo, 1989; Hu and Stamnes, 1993) or based on the water content/optical depth (Fouquart and Bonnel, 1980; Fouquart, 1985; Räisänen, 1999). Using the parameterization methodology of Fouquart (1985), single-scattering albedo $(\omega)$ for water clouds is estimated for different values of cloud optical depth. The parameterization equation can be expressed as (Fouquart, 1985)

$\omega=1-\left(9 \times 10^{-4}+2.75 \times 10^{-3}(\mu+1) \exp (-0.09 \tau)\right)$,

where $\mu$ is the solar zenith angle and $\tau$ is the cloud optical depth. This equation is based on calculations for a lowertropospheric cloud with a specific drop size distribution having effective radius of $9.9 \mu \mathrm{m}$. Using the above formula, SSA 
values were calculated for water clouds with varying optical depth and used in the present study. Unlike water clouds, spherical particle assumption is not valid in determining the single-scattering properties of ice clouds since they take on a variety of shapes like plates, hexagonal crystals and bullet rosettes (Schmidt et al., 1995). Because of this, singlescattering albedo of ice clouds is defined mainly by the effective cloud particle size (Hu and Stamnes, 1993; Fu, 1996). The effective particle size of a ice cloud can be mathematically defined as

$$
R=3 / 4 \frac{\int_{L_{\min }}^{L_{\max }} V(L) n(L) \mathrm{d} L}{\int_{L_{\min }}^{L_{\max }} A(L) n(L) \mathrm{d} L},
$$

where $L$ is the dimension of an ice crystal, $V(L)$ is the volume of the crystal, $A(L)$ is the projected area and $n(L)$ is the size distribution. The parameterization scheme takes into account the effective size of ice crystal, which removes the ambiguity regarding the particle shape and size from the SSA estimation. The single-scattering albedo of an ice crystal can be expressed as (Key et al., 2002)

$\omega_{i}=b_{0}+b_{1} R+b_{2} R^{2}+b_{3} R^{3}$,

where $b_{0}, b_{1}, b_{2}$, and $b_{3}$ are the empirical coefficients determined through regression for different SW spectral bands (i) and $R$ is the mean ice particle size (estimated from CERES SRBAVG2-GEO data). The bulk single-scattering albedo $(\omega)$ of ice crystals for the entire SW band is computed by integrating the individual SSA values computed for different shortwave bands and expressed mathematically as (Slingo and Schrecker, 1982; Chou et al., 1998)

$\omega=\frac{\sum \beta_{i}(\lambda) \omega_{i}(\lambda) S(\lambda)}{\sum \beta_{i}(\lambda) S(\lambda)}$,

where $\beta$ is the mean extinction coefficient and $S$ is normalized irradiance in each spectral band. The above parameterization scheme for ice cloud single-scattering albedo is an extension of the Streamer radiative transfer model (Key and Schweiger, 1998), which has been validated for different ice crystal size distributions and habits. Using this method, SSA values are computed for ice cloud particles and used in the computation of TOA flux. Using these SSA parameterization schemes, a cloud vertical model delineating the effective cloud cover and SSA is developed and used to model the TOA flux and CRF.

\section{Radiative characteristics of convective clouds over the Indian region}

Figure $2 \mathrm{a}$ and $\mathrm{b}$ show the seasonal mean variation in SWCRF and LWCRF, respectively, over the Indian region during the summer monsoon season of 2002-2005 derived from the CERES TOA flux data. From Fig. 2, it can be seen that large positive LWCRF values $\left(>60 \mathrm{Wm}^{-2}\right)$ and negative SWCRF values $\left(<-100 \mathrm{Wm}^{-2}\right)$ are observed over oceanic (northern Bay of Bengal and northeast Arabian Sea) and land regions alike (coastal Myanmar, Thailand, Cambodia, inland regions of China and Western Ghats). The absolute magnitude of SWCRF is greater than LWCRF over regions where LWCRF values exceed $60 \mathrm{Wm}^{-2}$ (similar observations were also reported by Rajeevan and Sreenivasan (2000) using ERBE data). Absolute values of LWCRF and SWCRF show relatively lower values over the rest of the oceanic and land areas. Figure 3 shows the seasonal mean variation in NETCRF over the Indian region during the summer monsoon season of 2002-2005. From Fig. 3, it can be seen that seasonal mean NETCRF shows large variation over the Indian region with values ranging from +30 to $-80 \mathrm{Wm}^{-2}$. No specific pattern exists in the regional variation in NETCRF over the Indian region. Based on the seasonal mean variation in NETCRF, the Indian region can be categorized into three distinct NETCRF regimes: (a) a positive NETCRF regime $\left(>20 \mathrm{Wm}^{-2}\right.$ ) over the south of the Indian land mass as well as over the Sri Lankan region; (b) near-zero NETCRF (between +20 and $-20 \mathrm{Wm}^{-2}$ ) over the oceanic regions to south of the Indian land mass as well as over northern India; and (c) a negative NETCRF regime $\left(<-20 \mathrm{Wm}^{-2}\right)$ over the northern Bay of Bengal close to the coast of Myanmar, Bangladesh, Myanmar, inland china and over the northeastern Arabian Sea as well as over the Western Ghats. In the present study, we focus mainly on the negative NETCRF regimes over the Indian region (delineated by black boxes in Fig. 3). They are designated as (1) the Bay of Bengal (10$22^{\circ} \mathrm{N}, 85-100^{\circ} \mathrm{E}$ ) region representing an oceanic regime, (2) Myanmar $\left(15-20^{\circ} \mathrm{N}, 92-100^{\circ} \mathrm{E}\right)$ and (3) the Western Ghats $\left(10-20^{\circ} \mathrm{N}, 72-77^{\circ} \mathrm{E}\right)$ representing a land regime.

Table 1 presents the seasonal mean TOA flux and CRF estimated from CERES data for the three regions during summer monsoon season of 2002-2005. In general, clear-sky SW and LW flux values are relatively lower over the Bay of Bengal region. The mean SWCRF and LWCRF values are larger (in magnitude) over the Bay of Bengal (BOB) compared to Myanmar (MYN) and the Western Ghats (WGS). In all the three regions, the absolute value of SWCRF is larger than LWCRF, indicating imbalance between the two. The mean NETCRF estimated for the three regions varies between -30 and $-37 \mathrm{Wm}^{-2}$, with largest values (in absolute magnitude) observed over the Myanmar region. However, mean NETCRF values estimated for the three regions (shown in Table 1) do not bring out the complete picture without quantifying the uncertainties associated with it. Using methodology described in Sect. 2.2, the uncertainty associated with the CERES TOA flux and NETCRF for the three regions is computed and presented in Tables 2 and 3, respectively. Table 2 presents various uncertainties associated with CERES TOA flux values over the three regions. Using these 

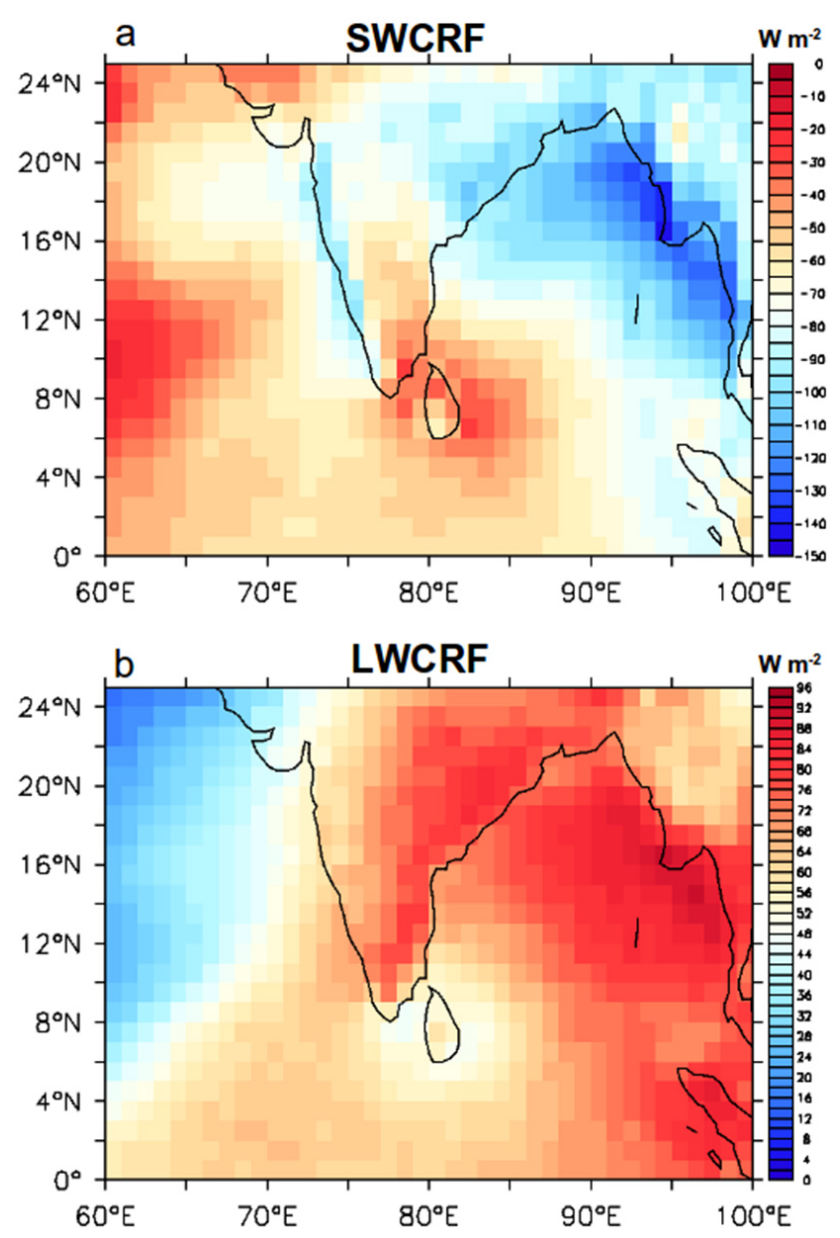

Figure 2. Seasonal mean variation in (a) SWCRF and (b) LWCRF over the Indian region during the summer monsoon season of 20022005. The color bar represents the CRF values in $\mathrm{Wm}^{-2}$.

values as input to Eq. (6), total uncertainty in the NETCRF for the three regions are computed and presented in Table 3. In general, the total uncertainty in the estimated NETCRF from CERES TOA flux measurements varies between 3 and $6 \mathrm{Wm}^{-2}$. Estimated uncertainty values are smallest for the Bay of Bengal region and largest for the Western Ghats. It must be noted that total uncertainty in the CERES NETCRF measurements are much lower compared to that from ERBE NETCRF measurements (Wielicki et al., 1995; Cess et al., 2001).

\subsection{Cloud characteristics over the Indian region}

Figure $4 \mathrm{a}$ and $\mathrm{b}$ depict the seasonal mean variation in cloud area fraction (in percent) for the high- and upper-middlelevel clouds over the Indian region during the summer monsoon season estimated from CERES cloud data. Only high- and upper-middle-level cloud fractions are shown in Fig. 4, since fractional coverage of lower-middle and lowlevel clouds are relatively lower ( $\sim 10 \%$ or less) over most

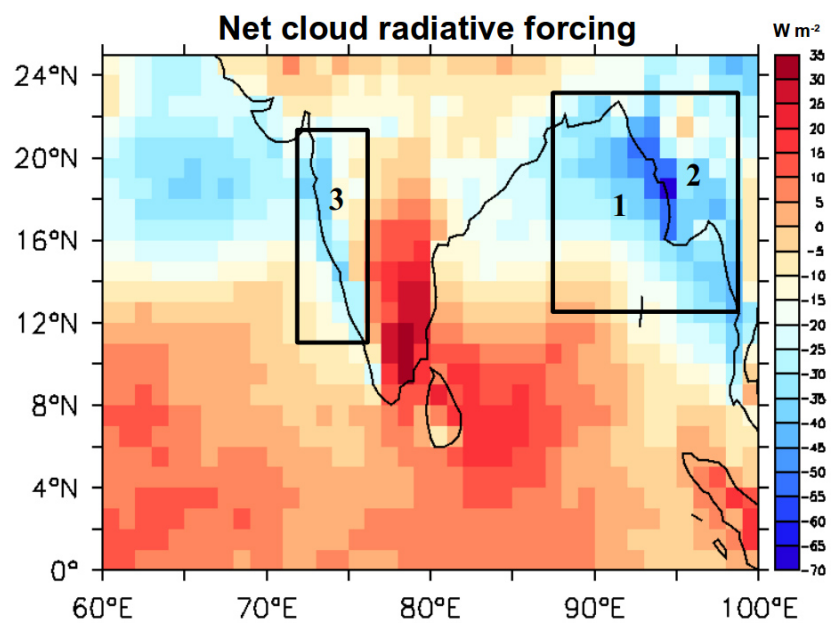

Figure 3. Seasonal mean map of NETCRF over the Indian region during the summer monsoon season of 2002-2005. The negative NETCRF regimes - (1) Bay of Bengal, (2) Myanmar and (3) the Western Ghats (marked in boxes) - are also shown. The color bar represents the NETCRF values in $\mathrm{Wm}^{-2}$.

Table 1. Mean values of TOA flux and CRF (in $\mathrm{Wm}^{-2}$ ) estimated for the three negative NETCRF regimes for the summer monsoon season of 2002-2005.

\begin{tabular}{lrrr}
\hline & $\begin{array}{r}\text { Bay of } \\
\text { Bengal }\end{array}$ & Myanmar & $\begin{array}{r}\text { Western } \\
\text { Ghats }\end{array}$ \\
\hline Clear SW & 45.6 & 64.5 & 61.9 \\
Total SW & 159 & 173.6 & 156.1 \\
Clear LW & 276.7 & 274.9 & 282.7 \\
Total LW & 194.1 & 202.6 & 219.7 \\
SWCRF & -113.4 & -109.1 & -94.2 \\
LWCRF & 82.6 & 72.3 & 63 \\
NETCRF & -30.8 & -36.8 & -31.2 \\
\hline
\end{tabular}

of the negative NETCRF regions. From Fig. 4a, it can be seen that high-cloud fraction is relatively large (> $40 \%$ ) over the northern Bay of Bengal and land areas over eastern India compared to that observed ( $20-30 \%)$ over oceanic regions to the south and the Western Ghats. In contrast, middlelevel cloud fraction shows large values $(\sim 40 \%)$ compared to high-cloud fraction over coastal regions of Myanmar, Thailand and Cambodia, as well as over the Western Ghats over the Indian peninsula. From Fig. 4, it can be observed that the three negative NETCRF regions (in Fig. 3) are characterized by large values of high- and middle-level cloud fraction compared to the rest of the Indian region. High-cloud fraction dominates the cloudiness over the Bay of Bengal region, while upper-middle and high-cloud fractions dominate the land NETCRF regimes. However, differentiating the negative NETCRF regimes merely based on the cloud cover data alone is inadequate. In order to have a quantitative understanding regarding parameters influencing the three negative 
Table 2. Estimated uncertainties (in $\mathrm{Wm}^{-2}$ ) in the mean CERES TOA SW and LW fluxes due to various error sources for the Bay of Bengal (BOB), Myanmar (MYN) and the Western Ghats (WGS) region.

\begin{tabular}{|c|c|c|c|c|c|c|c|c|}
\hline \multirow[t]{2}{*}{ Flux } & \multirow[t]{2}{*}{ Calibration } & \multirow[t]{2}{*}{ Algorithm } & \multicolumn{3}{|c|}{$\begin{array}{c}\text { Sampling } \\
\text { uncertainty }\left(\mathrm{Wm}^{-2}\right)\end{array}$} & \multicolumn{3}{|c|}{$\begin{array}{c}\text { Total } \\
\text { uncertainty }\left(\mathrm{Wm}^{-2}\right)\end{array}$} \\
\hline & & & BOB & MYN & WGS & ВOB & MYN & WGS \\
\hline TSW & 1 & 1 & 1.3 & 1.8 & 3.6 & 1.9 & 2.3 & 3.8 \\
\hline TLW & 1.3 & 1.9 & 0.9 & 2.1 & 1.8 & 2.4 & 3.1 & 2.9 \\
\hline CSW & 0.5 & 1.6 & 2.0 & 2.9 & 3.7 & 2.6 & 3.4 & 4.1 \\
\hline CLW & 1 & 3.3 & 1.03 & 1.05 & 1.2 & 3.6 & 3.6 & 3.7 \\
\hline
\end{tabular}

Table 3. Estimated uncertainty (in $\mathrm{Wm}^{-2}$ ) in the seasonal mean CERES NETCRF over the Bay of Bengal, Myanmar and the Western Ghats.

\begin{tabular}{lrrr}
\hline $\begin{array}{l}\text { Region of } \\
\text { interest }\end{array}$ & $\begin{array}{r}\text { Contribution of } \\
\text { 1st term in Eq. (6) }\end{array}$ & $\begin{array}{r}\text { Contribution of } \\
\text { 2nd term in Eq. (6) }\end{array}$ & $\begin{array}{r}\text { Total uncertainty }(\delta y) \\
\text { in NETCRF }\left(W^{-2}\right)\end{array}$ \\
\hline Bay of Bengal & 29.6 & -18.1 & 3.4 \\
Myanmar & 39.2 & -19.7 & 4.4 \\
Western Ghats & 52.9 & -18.6 & 5.8 \\
\hline
\end{tabular}

NETCRF regimes, seasonal mean variation in various cloud and environmental parameters over these regions are examined.

The seasonal mean values of cloud parameters (cloud fraction, particle size, optical depth) and environmental variables (rain rate, free-tropospheric humidity (FTH), precipitable water) over the three negative NETCRF regions are calculated for the summer monsoon season of 2002-2005 and are shown in Table 4. From Table 4, it can be seen that high- and upper-middle cloud fractions dominate the total cloudiness over the three regions. High-cloud amount ( $\sim 51 \%)$ and optical depth $(\sim 14)$ are largest over the Bay of Bengal, while upper-middle cloud amount shows large values ( $34 \%$ and $43 \%$ ) compared to high-cloud amount over the land areas. The amount of lower-level (lower middle and low) clouds is below $10 \%$ over the Bay of Bengal, while it shows values between 10 and $15 \%$ over land regions. Earlier studies have shown that high-clouds account for $\sim 65 \%$ of all cloud grids observed over the Indian monsoon region during the monsoon season (Tang and Chen, 2006; Meenu et al., 2007). Relatively lower values of low-level clouds (compared to high- and middle-level clouds) are observed over the three regions, which could be due to underestimation of low-level clouds by MODIS and geostationary instruments over the Indian monsoon region (Tang and Chen, 2006). The mean ice and water cloud particle size for the three regions shows similar values, while precipitable water vapor values (from GMAO GEOS database) show a variation between 48 and $58 \mathrm{~mm}$ for the three regions. From this analysis, it is not easy to comprehend the influence of various parameters on the negative NETCRF over these regions. In order to obtain a better understanding regarding the influence of these parameters on the negative NETCRF over the three regions, TOA flux and CRF values for the three regions are computed using RRTM simulations. The regional mean values of various cloud and environmental variables estimated for the three regions are used as input in the model. Using the cloud cover and cloud particle size data from CERES, altitude profile of cloud cover and SSA for each region is developed employing the parameterization schemes described in Sect. 3. TOA flux values estimated using the RRTM simulations for the three regions are used to compute the NETCRF.

\section{Validation of TOA flux and CRF: model vs. observations}

The seasonal mean TOA flux estimated for the three negative NETCRF regions from CERES, ISCCP-FD and RRTM simulations are shown in Table 5. The ISCCP-FD TOA flux data belonging to the study period are used in the estimation of seasonal mean TOA flux and CRF. In general, TOA fluxes from CERES observations and RRTM simulations are very much in agreement with each other. However, TOA flux derived from ISCCP-FD flux data shows consistently larger values $\left(\sim 5-10 \mathrm{Wm}^{-2}\right)$ compared to CERES and RRTM estimations. For example, CERES TOA clear-sky SW flux values (in $\mathrm{Wm}^{-2}$ ) are 46.8, 63.4, and 61.9 over the Bay of Bengal, Myanmar and the Western Ghats, respectively, while the same from ISCCP-FD (in $\mathrm{Wm}^{-2}$ ) are 55.4, 71 and 68.6, indicating an overestimation (on the order of $7-9 \mathrm{Wm}^{-2}$ ) by the ISCCP-FD data. Significant variations between the CERES- and RRTM-derived fluxes are observed only in the case of total-sky flux estimated over Myanmar and the Western Ghats region. Using the TOA flux values (presented in Table 5), SW, LW and NET CRF values for the three regions 
Table 4. Seasonal mean values of cloud micro/macrophysical properties and environmental variables over the three negative NETCRF regimes for the period of June-September (2002-2005).

\begin{tabular}{|c|c|c|c|c|c|c|c|c|c|}
\hline \multirow[t]{2}{*}{ Region } & \multicolumn{4}{|c|}{$\begin{array}{l}\text { Cloud cover }(\%) \text { and cloud optical } \\
\text { depth }\end{array}$} & \multicolumn{2}{|c|}{$\begin{array}{l}\text { Cloud particle } \\
\text { radius }(\mu \mathrm{m})\end{array}$} & \multirow[t]{2}{*}{$\begin{array}{r}\text { FTH } \\
(\%)\end{array}$} & \multirow[t]{2}{*}{$\begin{array}{r}\mathrm{PW} \\
(\mathrm{cm})\end{array}$} & \multirow[t]{2}{*}{$\begin{array}{r}\text { Rain } \\
\left(\mathrm{mm} \mathrm{h}^{-1}\right)\end{array}$} \\
\hline & High & Upper middle & Lower middle & Lower & Ice & Water & & & \\
\hline $\begin{array}{l}\text { Bay of Bengal } \\
\left(10-22^{\circ} \mathrm{N}, 85-100^{\circ} \mathrm{E}\right)\end{array}$ & $\begin{array}{r}51.6 \\
(14.8)\end{array}$ & $\begin{array}{l}25.6 \\
(4.9)\end{array}$ & $\begin{array}{r}4.7 \\
(3.2)\end{array}$ & $\begin{array}{r}5 \\
(2.5)\end{array}$ & 24.8 & 13.9 & 42.2 & 5.7 & 0.42 \\
\hline $\begin{array}{l}\text { Western Ghats } \\
\left(10-20^{\circ} \mathrm{N}, 72-77^{\circ} \mathrm{E}\right)\end{array}$ & $\begin{array}{r}22 \\
(10)\end{array}$ & $\begin{array}{l}34.1 \\
(7.2)\end{array}$ & $\begin{array}{r}13.5 \\
(7.1)\end{array}$ & $\begin{array}{l}14 \\
(5)\end{array}$ & 24.6 & 12.7 & 36.9 & 4.8 & 0.36 \\
\hline $\begin{array}{l}\text { Myanmar } \\
\left(15-20^{\circ} \mathrm{N}, 92-100^{\circ} \mathrm{E}\right)\end{array}$ & $\begin{array}{l}32.4 \\
(12)\end{array}$ & $\begin{array}{l}43.2 \\
(8.8)\end{array}$ & $\begin{array}{r}12.5 \\
(7)\end{array}$ & $\begin{array}{r}4.5 \\
(4.8)\end{array}$ & 23.2 & 13.3 & 37.8 & 5.6 & 0.38 \\
\hline
\end{tabular}

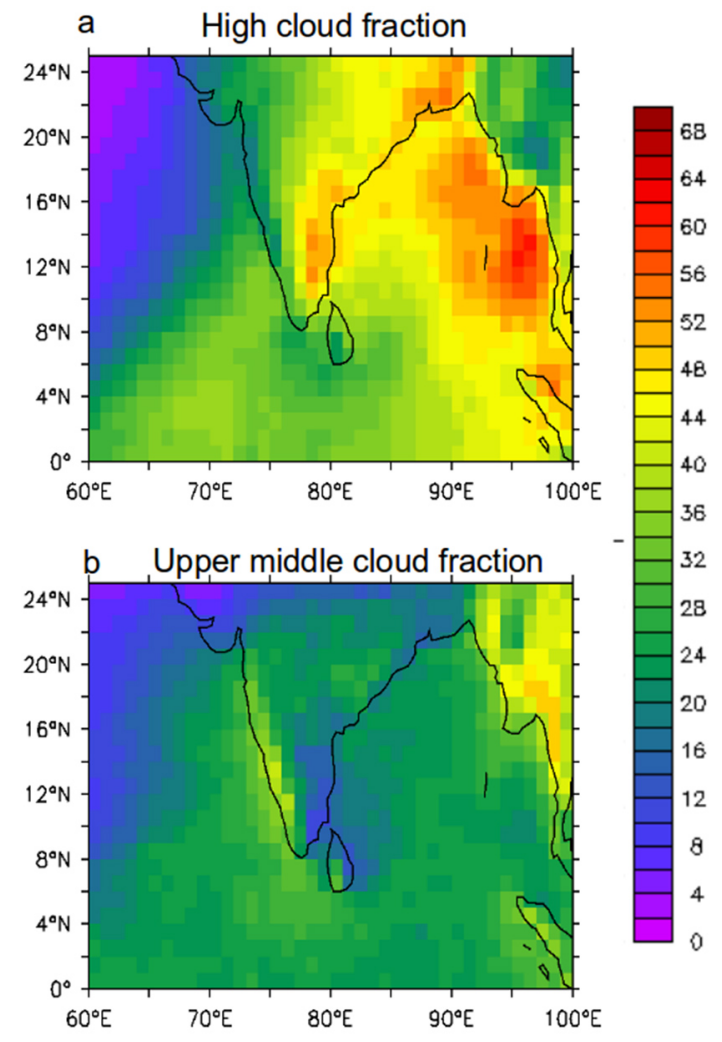

Figure 4. Seasonal mean variation in (a) high-cloud fraction (\%) and (b) upper-middle cloud fraction (\%) over the Indian region during the summer monsoon season of 2002-2005. The color bar represents the mean cloud fraction in percent.

are calculated and presented in Table 6. From Table 6, it can be seen that the CERES- and RRTM-derived CRF values are very much in agreement over the Bay of Bengal region, whereas the ISCCP-FD-derived values show considerable differences $\left(4-8 \mathrm{Wm}^{-2}\right)$. Over the land regions, both the RRTM- and ISCCP-derived SW and LW CRF values show substantial variation from CERES-derived values. Still, RRTM-derived SW and LW CRF values are much closer to
Table 5. Intercomparison of CERES TOA flux (bold) with that estimated from RRTM simulations (italicized) and ISCCP-FD flux (third) for the Bay of Bengal, Myanmar and the Western Ghats regions, respectively.

\begin{tabular}{lrrr}
\hline $\begin{array}{l}\text { TOA } \\
\text { flux }\end{array}$ & $\begin{array}{r}\text { Bay of } \\
\text { Bengal }\end{array}$ & Myanmar & $\begin{array}{r}\text { Western } \\
\text { Ghats }\end{array}$ \\
\hline Clear SW & $\mathbf{4 5 . 6}$ & $\mathbf{6 4 . 5}$ & $\mathbf{6 1 . 9}$ \\
$\left(\right.$ Wm $\left.^{-2}\right)$ & 46.8 & 63.4 & 61.9 \\
& 55.4 & 71 & 68.6 \\
\hline Total SW & $\mathbf{1 5 9}$ & $\mathbf{1 7 3 . 6}$ & $\mathbf{1 5 6 . 1}$ \\
$\left(\right.$ Wm $\left.^{-2}\right)$ & 160.1 & 166 & 151.4 \\
& 162.6 & 181.9 & 154.1 \\
\hline Clear LW & $\mathbf{2 7 6 . 7}$ & $\mathbf{2 7 4 . 9}$ & $\mathbf{2 8 2 . 7}$ \\
$\left(\right.$ Wm $\left.^{-2}\right)$ & 276.9 & 275.1 & 284.7 \\
& 278.7 & 276.2 & 280.5 \\
\hline Total LW $^{-2}$ & $\mathbf{1 9 4 . 1 4}$ & $\mathbf{2 0 2 . 6}$ & $\mathbf{2 1 9 . 7}$ \\
$\left(\right.$ Wm $\left.^{-2}\right)$ & 195.9 & 209.6 & 225.6 \\
& 206.2 & 215.2 & 231.2 \\
\hline
\end{tabular}

the CERES-derived values compared to that from ISCCPFD. The NETCRF estimated from the CERES and RRTM shows very good agreement (within the uncertainty limit of CERES observations), while the ISCCP values are well outside the uncertainty limit of CERES observation.

The NETCRF estimated from ISCCP-FD data over the three regions shows consistently large values (in magnitude) compared to CERES- and RRTM-derived values. This indicates that the cloud vertical model used in the estimation of TOA flux (RRTM) for the three negative NETCRF regimes is more accurate in representing the cloud overlap and altitude structure compared to the cloud vertical structure (CVS) scheme used in the ISCCP-FD flux estimation. However, it can be argued that the ISCCP CVS scheme is a general overlap scheme applicable for a broad range of meteorological conditions, while the present cloud overlap scheme is tailored for a specific convective cloud condition. 
Table 6. Intercomparison of SWCRF, LWCRF and NETCRF (in $\mathrm{Wm}^{-2}$ ) from CERES observations (bold) with that calculated from RRTM simulations (italicized) and ISCCP-FD flux (third value) for the Bay of Bengal, Myanmar and the Western Ghats regions. Uncertainty associated with CERES NETCRF values are also provided (values after the \pm sign).

\begin{tabular}{|c|c|c|c|}
\hline $\begin{array}{l}\text { TOA } \\
\text { CRF }\end{array}$ & $\begin{array}{l}\text { Bay of } \\
\text { Bengal }\end{array}$ & Myanmar & $\begin{array}{r}\text { Western } \\
\text { Ghats }\end{array}$ \\
\hline SWCRF & $\begin{array}{l}-\mathbf{1 1 3 . 4} \\
-113.3 \\
-107.2\end{array}$ & $\begin{array}{l}-\mathbf{1 0 9 . 1} \\
-102.6 \\
-110.9\end{array}$ & $\begin{array}{l}-94.2 \\
-89.5 \\
-85.5\end{array}$ \\
\hline LWCRF & $\begin{array}{r}82.6 \\
81 \\
72.6\end{array}$ & $\begin{array}{l}72.3 \\
65.5 \\
61.1\end{array}$ & $\begin{array}{r}\mathbf{6 3} \\
59.2 \\
49.4\end{array}$ \\
\hline NETCRF & $\begin{array}{r}-\mathbf{3 0 . 8} \pm \mathbf{3 . 4} \\
-32.3 \\
-34.6\end{array}$ & $\begin{array}{r}\mathbf{- 3 6 . 8} \pm \mathbf{4 . 4} \\
-37 \\
-49.8\end{array}$ & $\begin{array}{r}-\mathbf{3 1 . 2} \pm \mathbf{5 . 8} \\
-30.3 \\
-36.1\end{array}$ \\
\hline
\end{tabular}

The disparity in SW and LW CRF values computed by the RRTM and CERES over the land regimes (Myanmar and the Western Ghats) can be attributed to the underlying uncertainty associated with the parameterization of cloud vertical structure and its microphysical properties. After successfully simulating the negative NETCRF regimes over the Indian region using RRTM, the next step is to identify the parameters that control the negative NETCRF over these regions. This is carried out by analyzing the sensitivity of cloud radiative forcing to various cloud and environmental variables (using RRTM), and is explained in the subsequent sections.

\subsection{Sensitivity calculations}

In this section, the sensitivity of CRF to various cloud macro/microphysical properties and environmental variables is analyzed by studying their relative contribution to the NETCRF. In the previous section, it was shown that negative NETCRF over the three regions could be modeled with good accuracy using RRTM and cloud parameterization schemes. Using the same simulation methods, it is possible to quantify the dependence of NETCRF on various cloud micro/macrophysical and environmental variables over the three regions. This also provides an opportunity to test the veracity of theoretical hypothesis propagated by various investigators on the occurrence of negative NETCRF over tropical convective regions. In this analysis, the influence of cloud amount, cloud particle size, single-scattering albedo and atmospheric water vapor on the negative NETCRF over the three regions is examined.

\subsubsection{Influence of cloud macrophysical properties on CRF}

In the first simulation, the influence of cloud-top altitude on the LW and SW CRF values is examined for the three regions. In this analysis, TOA flux values are computed using RRTM for the three regions by varying the cloud-top altitude in the respective cloud vertical model from 125 to $400 \mathrm{hPa}$ in several steps while keeping all other input parameters constant. The resultant LW and SW CRF for different cloud-top pressures over the Bay of Bengal (thick line) and Myanmar (dashed line) region is estimated and shown in Fig. 5. From Fig. 5, it can be seen that LWCRF decreases monotonically with an increase in the cloud-top pressure (from $\sim 100$ and $80 \mathrm{Wm}^{-2}$, respectively, to $\sim 45$ and $40 \mathrm{Wm}^{-2}$, respectively, for increase in cloud-top pressure from 100 to $400 \mathrm{hPa}$ ) for the two regions, while the SWCRF shows very little variation $\left(<5 \mathrm{Wm}^{-2}\right)$. This indicates that change in cloud-top altitude of high clouds causes relatively large variation in LWCRF $\left(\sim 50 \mathrm{Wm}^{-2}\right)$ compared to SWCRF, which results in causing an imbalance between the two. The sharp wedge observed in the SWCRF variation in Fig. 5 is due to the change in cloud cover type from high level to middle level. These results are in agreement with that of Kiehl (1994), who showed that a decrease (increase) in cloud-top altitude causes the system to shift towards a negative (positive) NETCRF regime. However, seasonal mean cloud-top altitude (high clouds) over the Indian region during monsoon season shows a variation between 180 and $240 \mathrm{hPa}$. For such variation in cloud-top altitude, corresponding variations in LWCRF observed for the three regions are less than $13 \mathrm{Wm}^{-2}$. This shows that small variation in cloud-top altitude of high clouds cannot significantly influence the magnitude of NETCRF over the Indian region.

In the second sensitivity analysis, we try to quantify the competing influence of cloud top and cloud amount on the LWCRF and NETCRF. In this analysis, high-cloud amount in the cloud vertical model representing the Bay of Bengal regime is varied from its original value of $50 \%$ to $20 \%$ in steps of $10 \%$, keeping cloud amount of other groups in the cloud vertical model same. By stepwise reduction in highcloud amount from the cloud vertical model, the fraction of upper-middle-level clouds exposed to the TOA (and to the incoming solar incoming radiation) increases from 12 to $42 \%$. Running RRTM with this modified cloud vertical profile shows a decrease in LWCRF from 78 to $66 \mathrm{Wm}^{-2}$, while the SWCRF shows very little variation since the total cloud cover remains the same (top-level clouds are sliced off, while bottom-level clouds remain intact). This reduction in high-cloud amount increases the absolute magnitude of NETCRF (by $\sim 12 \mathrm{Wm}^{-2}$ ) due to a decrease in LWCRF and shift the region towards a stronger negative regime. A similar analysis was performed for the Myanmar and the Western Ghats region, where it showed similar result to that of the Bay of Bengal region. Cess et al. (2001) observed that 

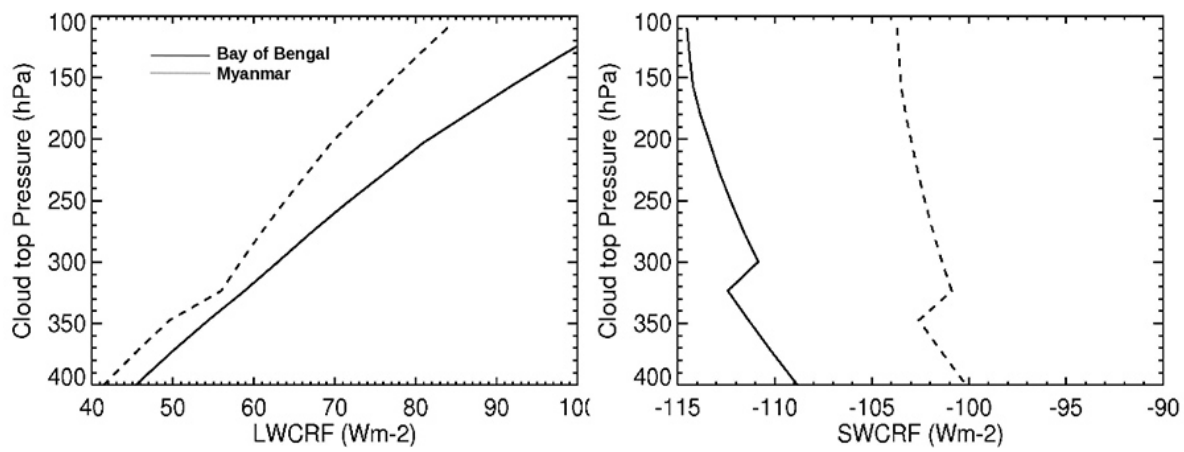

Figure 5. Variation in LWCRF (left panel) and SWCRF (right panel) values with cloud-top pressure for the Bay of Bengal (thick line) and Myanmar region (dashed line), respectively, estimated using RRTM.

change in cloud vertical structure associated with El Niño over the tropical Pacific Ocean tends to cause substantial radiative cooling. It was observed that CRF over Pacific warm pool is partially governed by high and middle-level clouds during the El Niño year compared to high-level clouds during normal years. This analysis indicates that in a multilayered cloud system, both cloud vertical structure and cloud amount influence the NETCRF, even though the magnitude of variation in NETCRF is not significantly large in this case.

In the third test, the influence of low-level clouds on the NETCRF is examined over the three regions while keeping all other parameters in the cloud vertical model constant. In this analysis, unobscured portions (visible from TOA) of the low-level clouds are removed from the cloud vertical profile and LWCRF and SWCRF values are recomputed using the modified cloud vertical model. The modified LW and SW CRF values estimated from the analysis are presented in Table 7. From Table 7, it can be seen that the low-level cloud cover over these regions has very little influence in controlling the observed LWCRF and SWCRF compared to highlevel clouds. The SWCRF over the Western Ghats shows a decrease $\left(\sim 7 \mathrm{Wm}^{-2}\right)$ when the modified cloud vertical profile (low-level clouds removed) is used. For the Bay of Bengal and Myanmar region, the maximum decrease in SWCRF is on the order of $<3 \mathrm{Wm}^{-2}$. Corresponding variation in the LWCRF is considerably small compared to that of SWCRF. The low-level cloud fraction show relatively large values $(\sim 14 \%)$ over the Western Ghats compared to other two regions $(<6 \%)$. Present analysis shows that low-level cloud amount has little influence in modulating the NETCRF values over the three study regions.

\subsubsection{Influence of cloud microphysical properties on CRF}

In the present analysis, influence of cloud single-scattering albedo and ice cloud particle size on NETCRF is investigated using RRTM. The layer-averaged cloud particle size (from SRBAVG2-GEO data) for ice clouds over the Indian region shows a variation in the range of $18-30 \mu \mathrm{m}$. Cloud ice
Table 7. RRTM simulation of SWCRF and LWCRF values (in $\mathrm{Wm}^{-2}$ ) for the three negative NETCRF regions by changing lowlevel cloud amount in the respective cloud vertical model.

\begin{tabular}{lrrr}
\hline \multicolumn{1}{c}{ Region } & \multicolumn{2}{c}{$\begin{array}{c}\text { CRF }\left(\mathrm{Wm}^{-2}\right) \text { values } \\
\text { estimated when } \\
\text { unobscured portions of } \\
\text { low-level clouds are } \\
\text { present or absent }\end{array}$} \\
\hline Bay of & SWCRF & -113.4 & -111.6 \\
Bengal & LWCRF & 81 & 80.8 \\
\hline Myanmar & SWCRF & -102.6 & 100.8 \\
& LWCRF & 65.5 & 65.2 \\
\hline Western & SWCRF & -89.5 & -82.5 \\
Ghats & LWCRF & 59.2 & 58 \\
\hline
\end{tabular}

particle size is directly related to the cloud single-scattering properties (Eq. 11), which in turn modulates the SWCRF and NETCRF of the cloud system. In the present analysis, an attempt is made to quantify the sensitivity of SWCRF to the ice cloud particle size. This is done by computing the SWCRF over the three regions by varying the ice particle size of high- and upper-middle-level clouds (there by varying the SSA) in the cloud vertical model while keeping all other parameters constant. The ice particle size is varied from 20 to $40 \mu \mathrm{m}$ and SWCRF values are computed each time using RRTM by incorporating the modified SSA in the input cloud model. SWCRF estimated from the model simulations is presented in Table 8. From Table 8, it can be seen that the SWCRF values show a monotonic decrease with increasing ice particle size for the three regions. A maximum decrease in SWCRF value of $\sim 10 \mathrm{Wm}^{-2}$ for an increase in ice particle size from 20 to $40 \mu \mathrm{m}$ is observed over the Bay of Bengal region, while it is much less over the other two regions. This study indicates that an increase in ice cloud particle size leads to a moderate decrease in SWCRF and NETCRF over 
Table 8. RRTM simulation of SWCRF $\left(\mathrm{Wm}^{-2}\right)$ using different ice particle size (varying SSA values) values in the cloud vertical model for the Bay of Bengal, Myanmar and the Western Ghats regions.

\begin{tabular}{crrr}
\hline $\begin{array}{c}\text { Ice particle } \\
\text { radius }(\mu \mathrm{m})\end{array}$ & $\begin{array}{r}\text { Bay of } \\
\text { Bengal }\end{array}$ & Myanmar & $\begin{array}{r}\text { Western } \\
\text { Ghats }\end{array}$ \\
\hline 20 & -116 & -104.3 & -90.6 \\
25 & -112.7 & -102.6 & -89.5 \\
30 & -109.6 & -101.1 & -88.5 \\
35 & -107.9 & -100.2 & -87.9 \\
40 & -106.2 & -99.3 & -87.3 \\
\hline
\end{tabular}

the study region. Studies have shown that changes in cloud particle (ice) size can modify the net radiative forcing of cirrus clouds to a cooling or warming regime depending on the direction of change (Zhang et al., 1999). However, it seems unlikely that small variation in cloud ice particle size (between 18 and $30 \mu \mathrm{m}$ ) over the Indian region alone can bring about the negative NETCRF values observed over the region.

\subsubsection{Influence of atmospheric water vapor on CRF}

In this section, sensitivity analyses carried out using RRTM to understand the influence of atmospheric water vapor on the LWCRF over the three negative NETCRF regions are explained. Studies have shown that atmospheric water vapor can significantly influence the LW forcing by reducing the clear-sky TOA flux (Sohn and Schmetz, 2004; Sohn and Bennartz, 2008). Water vapor, being an important greenhouse gas, absorbs the atmospheric LW radiation and decreases the LWCRF (while having little effect on SWCRF). Roca et al. (2004) proposed that damping of LWCRF by large amount of water vapor present in the atmosphere over the Bay of Bengal region during the summer monsoon season could be a reason for the observed negative NETCRF. Sohn et al. (2006) studied the variation in satellite-derived LWCRF due to the upper tropospheric water vapor change associated with cloud formation and showed that water vapor in the upper troposphere can contribute up to $\sim 12 \mathrm{Wm}^{-2}$ to the LWCRF over convectively active tropical regions. However, in their paper, Sohn et al. (2006) promote an alternative computation of LWCRF to the traditional one and use a composite of clear-sky pixels away from the region of interest (cloudy regions) to derive TOA LW clear-sky flux (in order to avoid cloud contamination). In the traditional LWCRF computation (used in the present study), TOA LW clear-sky flux estimation is based on subsampling of the region of interest under clear-sky conditions. Although CRF computations proposed by Sohn et al. (2006) might be a closer estimate of the cloud radiative effect, we have opted to use the traditional definition of the CRF mainly because it is readily available from satellite measurements. Since the Indian region during the summer monsoon season is mostly overcast, TOA clear-sky flux measurements (over $1^{\circ} \times 1^{\circ}$ latitude- longitude grid) from the CERES EBAF database are used. The CERES EBAF database uses the MODIS/Terra-derived narrow-band radiances (over $1 \mathrm{~km} \times 1 \mathrm{~km}$ pixel) from clearsky portions of the partly and mostly cloudy CERES footprints ( $20 \mathrm{~km}$ wide pixel) over the negative NETCRF regions to estimate the clear-sky TOA flux. Because of this method, TOA flux measured for clear- and total-sky using CERES instrument belongs to the same latitude-longitude grid, which to a certain extent reduces the water vapor difference between clear- and total-sky environment (but by no means getting rid of it completely).

In the present analysis, CRF over the three negative NETCRF regions is simulated by varying the PW vapor content in the atmosphere from their original values (between 48 and $58 \mathrm{~mm}$ ) while keeping all other parameters in model simulation constant. This is achieved by varying the relative humidity (thereby water vapor mixing ratio) of the free troposphere in the model atmosphere while keeping the boundary layer and stratospheric RH constant. This results in the formation of several model atmospheric profiles with distinctly different PW values (between 33 and $68 \mathrm{~mm}$ ). Using this methodology, variation in TOA LW flux and LWCRF with $\mathrm{PW}$ for the three regions is examined. The variation in TOA LW flux (clear- and total-sky) and LWCRF with PW for the Bay of Bengal region is shown in Fig. 6. In general, clearand total-sky LW flux shows a monotonic decrease with increase in PW. TOA LW clear-sky flux over the Bay of Bengal region shows a decrease of $\sim 45 \mathrm{Wm}^{-2}$ for an increase in PW value from 33 to $68 \mathrm{~mm}$, while the total-sky LW flux shows a decrease of $\sim 20 \mathrm{Wm}^{-2}$. The LWCRF also shows a considerable decrease over the Bay of Bengal region, from 106 to $74 \mathrm{Wm}^{-2}$ (decrease of $\sim 32 \mathrm{Wm}^{-2}$ ), for a corresponding increase in PW from 33 to $68 \mathrm{~mm}$. Over Myanmar and the Western Ghats, LWCRF shows a decrease of $\sim 30$ and $\sim 25 \mathrm{Wm}^{-2}$, respectively, for a similar variation in PW from 33 to $68 \mathrm{~mm}$. Sohn et al. (2006) demonstrated that water vapor in the upper troposphere can contribute $\sim 12 \mathrm{Wm}^{-2}$ to the LWCRF over convectively active tropical regions. This analysis shows that atmospheric water vapor can cause a relatively larger variation in LWCRF (and in NETCRF) compared to other variables discussed in earlier sections. For a thorough understanding, seasonal mean variation in PW over the Indian region during different seasons is also examined.

Seasonal mean variation in precipitable water vapor (from the CERES SRBAVG GEO/GMAO GEOS product) over the Indian region during the summer and winter months are estimated and shown in Fig. 7. From Fig. 7a and b, it can be seen that the average value of PW observed over the Indian region is between 40 and $60 \mathrm{~mm}$ (summer months), while it is between $\sim 20$ and $30 \mathrm{~mm}$ during the winter months (DJF). This indicates that between dry (winter) and wet (summer) seasons, PW content in the atmosphere over the Indian region increases by $\sim 25-35 \mathrm{~mm}$. RRTM simulations show that such an increase in PW can cause a substantial decrease in clear-sky TOA flux $\left(\sim 30-40 \mathrm{Wm}^{-2}\right)$ and LWCRF 

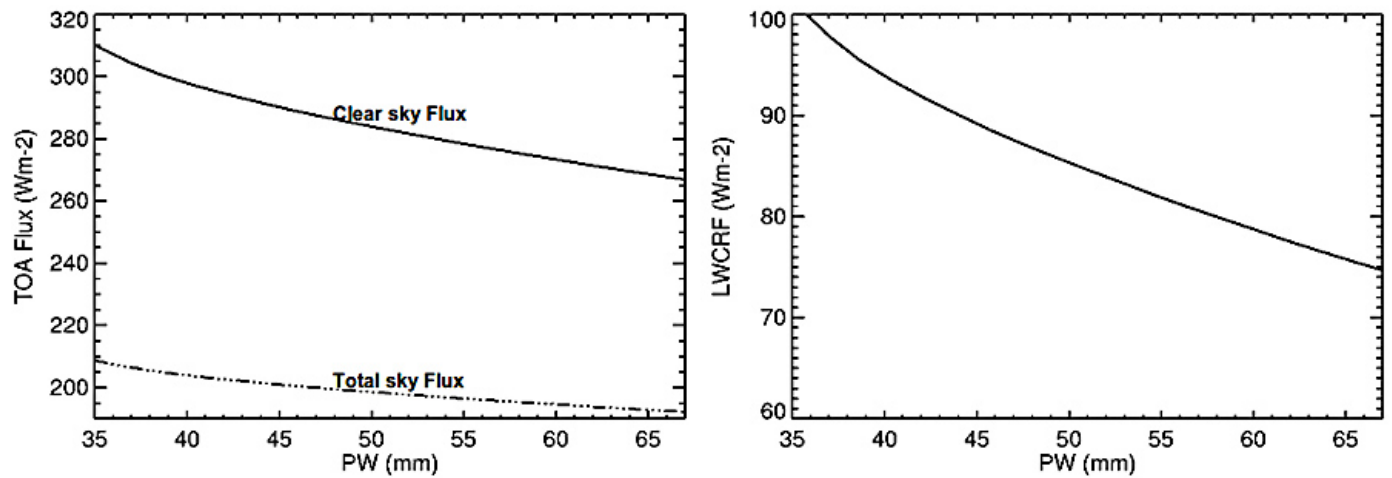

Figure 6. Variation in TOA LW clear- and total-sky flux (left panel) and LWCRF (right panel) with precipitable water (PW) over the Bay of Bengal region during the summer monsoon season using RRTM simulation.

$\left(\sim 20-30 \mathrm{Wm}^{-2}\right)$. From Fig. 6, it can be seen that LWCRF over the Bay of Bengal increases by $\sim 23 \mathrm{Wm}^{-2}$ for a decrease in PW content from 58 to $30 \mathrm{~mm}$. Over the two land regimes, a similar increase in LWCRF is observed, though the magnitude of increase in LWCRF is lower than that observed over the Bay of Bengal region. From this analysis, it can be seen that the atmospheric water content over these regions significantly modifies the observed LWCRF and NETCRF values. Hence, relatively large amount of water vapor in the atmosphere over the three negative NETCRF regions during the summer monsoon season is a major factor controlling the imbalance between SWCRF and LWCRF.

\section{Intercomparison of the oceanic NETCRF regimes: Bay of Bengal vs. western Pacific}

We now consider two specific oceanic convective regions for a better understanding of the negative and near-zero NETCRF regimes: the Bay of Bengal $\left(10-22^{\circ} \mathrm{N}, 85-\right.$ $100^{\circ} \mathrm{E}$ ) during the Asian monsoon season (represents negative regime) and the western Pacific $\left(10^{\circ} \mathrm{S}-10^{\circ} \mathrm{N}, 140-\right.$ $180^{\circ} \mathrm{E}$ ) during the March-April period (near-zero regime). The two regions share similar surface properties (ocean surface type) with almost similar sea surface temperature (SST). Figure 8 presents the mean variation in CERES TOA NETCRF over the western Pacific during the March-April period for the years 2002-2005. From Fig. 8, it can be seen that the regional variation in NETCRF over the western Pacific during this period lies mainly in the range of $\pm 20 \mathrm{Wm}^{-2}$. Negative NETCRF values $\left(\sim-20 \mathrm{Wm}^{-2}\right)$ are observed over small areas close to the Indonesian islands, while the rest of the region shows positive or near-zero NETCRF values. A similar regional variation in NETCRF over the Bay of Bengal (Fig. 3) region during the monsoon season shows negative NETCRF values ranging from -10 to $-70 \mathrm{Wm}^{-2}$. For a more quantitative assessment, the mean TOA flux and CRF over the two regions are estimated and presented in Table 9. In general, the TOA SW (clear and total) flux values are largest over the Bay of Bengal region compared to the western Pacific, while the reverse is true for TOA LW fluxes. Another interesting point here is the difference in clear-sky TOA LW flux between two regions: relatively lower TOA LW clear-sky flux $\left(276 \mathrm{Wm}^{-2}\right)$ values are observed over the Bay of Bengal compared to that over the western Pacific $\left(285 \mathrm{Wm}^{-2}\right)$. While LWCRF and SWCRF values over the Bay of Bengal region show large imbalance (resulting in a NETCRF value $\sim-30 \mathrm{Wm}^{-2}$ ), those over the western Pacific show a near balance between LWCRF and SWCRF (65 and $-67 \mathrm{Wm}^{-2}$, respectively), leading to nearzero NETCRF over the western Pacific. The disparity in the estimated CRF values observed over the two oceanic regions is evident in Table 9.

Table 10 presents the regional mean cloud fraction and cloud optical depth estimated using CERES data over the Bay of Bengal and the western Pacific. From Table 10, it can be seen that high-level cloud fraction $(\sim 51 \%)$ observed over the Bay of Bengal is relatively large compared to that observed over the western Pacific $(\sim 38 \%)$, while lower level cloud types show almost similar variation over the two regions. A comparison of cloud optical depth and cloud-top altitude between various cloud groups over the two regions also show similar variations. This indicates that cloud properties over the two convective regions show a lot of similarities, except for the high-level cloud fraction. However, the interesting question here is whether the variation observed in the cloud amount (13 and 5\% in high- and upper-middle cloud cover, respectively, between these two regions) alone can cause the NETCRF to shift between near-zero and negative values. Rajeevan and Sreenivasan (2000) postulated that a large high-cloud amount observed over the Bay of Bengal region is the reason behind the large negative NETCRF compared to the rest of the tropical convective regions. However, RRTM simulations incorporating the mean cloud and environmental variables over the western Pacific region show that such variability in cloud cover alone is not enough to drive 
Table 9. Seasonal mean values of TOA Flux $\left(\mathrm{Wm}^{-2}\right)$ and CRF $\left(\mathrm{Wm}^{-2}\right)$ over the Bay of Bengal and the western Pacific region for the period 2002-2005.

\begin{tabular}{lrr|rr|rrr}
\hline REGION & \multicolumn{2}{c|}{ Clear sky } & \multicolumn{2}{c|}{ Total sky } & SWCRF & LWCRF & NETCRF \\
\hline & SW & LW & SW & LW & & & \\
\hline $\begin{array}{l}\text { Bay of Bengal } \\
\text { (Jun-Sep) }\end{array}$ & 45.6 & 276.7 & 159 & 194.1 & -113.4 & 82.6 & -30.8 \\
$\begin{array}{l}\text { Western Pacific } \\
\text { (Mar-Apr) }\end{array}$ & 40 & 285.2 & 107.7 & 220 & -67.7 & 65.2 & -2.5 \\
\hline
\end{tabular}
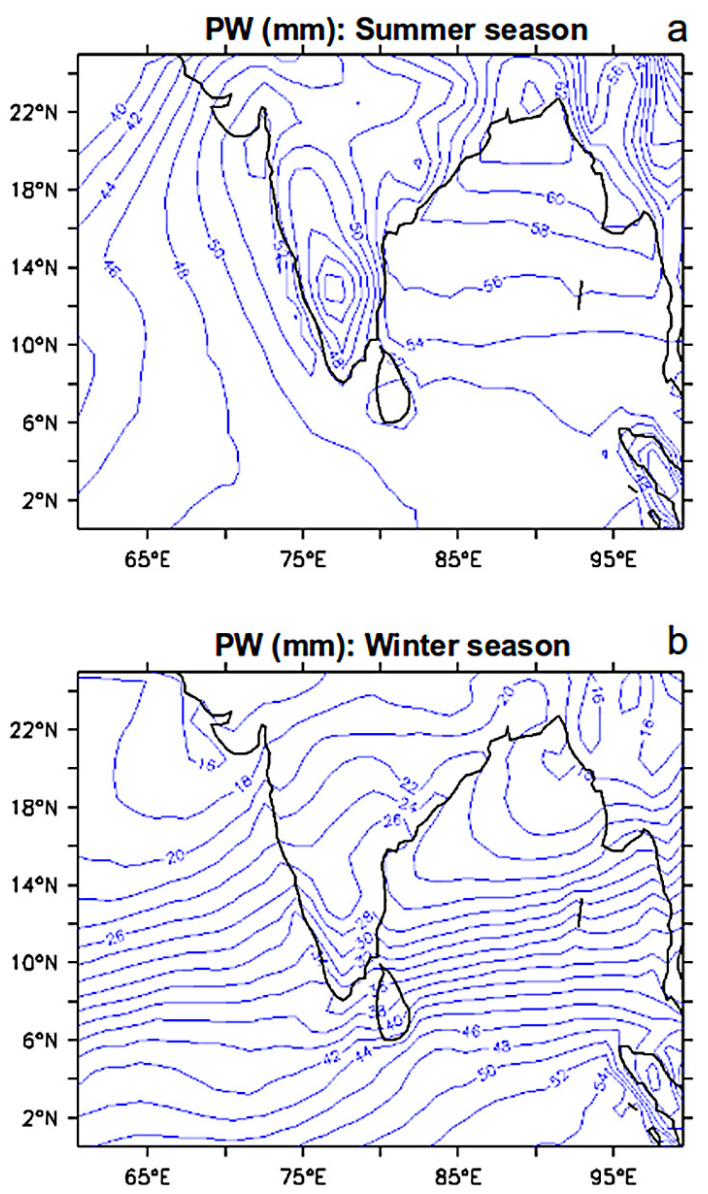

Figure 7. Contour plots of seasonal mean variation in precipitable water $(\mathrm{mm})$ content over the Indian region during the (a) summer monsoon season and (b) winter season for the period 2002-2005.

the system from a near-zero to a large negative NETCRF regime.

The other important parameters that can influence the NETCRF over the two regions are cloud microphysical properties (cloud particle size, shape, optical depth, etc.) and atmospheric water content. Model simulation of TOA flux over the negative NETCRF regions using RRTM showed that changes in cloud optical depth (COD) have very little influence in modulating the TOA flux when the COD values are

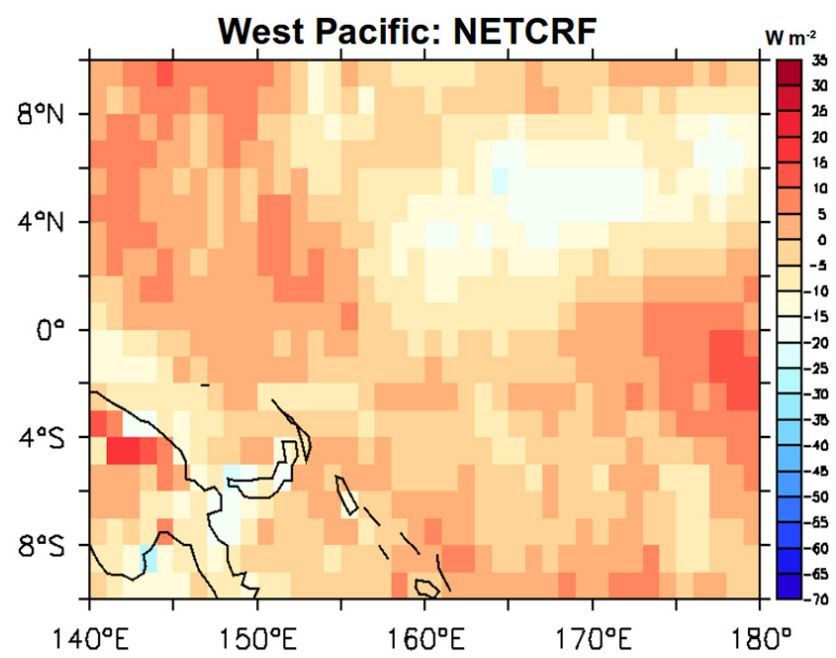

Figure 8. Seasonal mean variation in $\operatorname{NETCRF}\left(\mathrm{Wm}^{-2}\right)$ over the western Pacific region during the March-April period (2002-2005). The color bar represents the NETCRF values in $\mathrm{Wm}^{-2}$.

above a certain limit (COD > 8). Over the Bay of Bengal and the western Pacific, the observed cloud optical depth values for the high-level clouds are typically above this range where sensitivity of CRF to changes in COD is very much less. Comparison of cloud particle size $(\sim 25 \mu \mathrm{m}$ for ice and $\sim 12 \mu \mathrm{m}$ for water clouds, respectively) over the two regions shows very little variation. The other variable that can influence the NETCRF over the two regions is the atmospheric water vapor content. In Sect. 5.1.3, the influence of atmospheric water vapor on the TOA flux and CRF over the Indian region was discussed. A similar analysis is carried out to quantify the influence of atmospheric water vapor on the NETCRF over the western Pacific. For this purpose, monthly mean atmospheric water vapor content over the two regions from special sensor microwave/imager (SSM/I) data (Wentz, 1997) was estimated for the months of April (western Pacific) and July (Bay of Bengal) (2002-2005) and is shown in Fig. 9. The atmospheric water vapor content over the Bay of Bengal during July is extremely large (>58 mm) compared to that observed over the western Pacific region $(\sim 45$ $55 \mathrm{~mm}$ ) during April. Over the negative NETCRF regions $\left(<-30 \mathrm{Wm}^{-2}\right)$ of the Bay of Bengal, the PW reaches as high 
Table 10. Seasonal mean values of cloud fraction (\%) and cloud optical depth (in parentheses) over the Bay of Bengal and the western Pacific region for the period 2002-2005.

\begin{tabular}{lrrrr}
\hline REGION & \multicolumn{4}{c}{ Cloud cover (\%) and cloud optical depth } \\
\hline & High & Upper mid & Lower mid & Low \\
\hline $\begin{array}{l}\text { Bay of Bengal } \\
\text { (Jun-Sep) }\end{array}$ & $51.6(14.8)$ & $25.6(4.9)$ & $4.7(3.2)$ & $5(2.5)$ \\
$\begin{array}{l}\text { western Pacific } \\
\text { (Mar-Apr) }\end{array}$ & $38.5(12.7)$ & $20.1(4.6)$ & $4.3(3.5)$ & $7(2.3)$ \\
\hline
\end{tabular}

as $\sim 68 \mathrm{~mm}$. The water vapor information over the land is not available from SSM/I data. However, from Fig. 9, it can be seen that the water vapor amount progressively increases towards land area (coast of Myanmar) over the Bay of Bengal region. Large values of atmospheric water vapor $(>65 \mathrm{~mm})$ are observed over the Bay of Bengal region close to the coast Myanmar where the NETCRF values also show negative values $\left(<-30 \mathrm{Wm}^{-2}\right)$. Compared to the Bay of Bengal region, the water vapor loading over the western Pacific usually lies within $48-58 \mathrm{~mm}$ during April. Interannual variation in atmospheric water vapor content over the Bay of Bengal region shows that precipitable water vapor amount reaches as high as $\sim 70 \mathrm{~mm}$ over the core negative NETCRF regions during the summer monsoon seasons, while it hardly goes beyond $60 \mathrm{~mm}$ over the western Pacific during March-April. The redistribution of water vapor associated with convection results in increased moistening of the upper troposphere over the Indian region, which contributes significantly to the damping of LWCRF and creating an imbalance with SWCRF. The magnitude of such damping in LWCRF over the western Pacific is relatively small compared to the Bay of Bengal region. The increase in atmospheric water vapor content and high-cloud amount could be the reason behind negative NETCRF values being observed over the Bay of Bengal region compared to near-zero NETCRF values observed over the western Pacific region.

\section{Summary and discussion}

The net cloud radiative forcing over the Indian land mass and adjacent oceanic regions during the Asian summer monsoon season of 2002-2005 was investigated using CERES observations and RRTM simulations. The seasonal mean variation in NETCRF over the Indian region during the Asian summer monsoon season showed the existence of three strong negative NETCRF regimes: the Bay of Bengal $\left(\sim-31 \mathrm{Wm}^{-2}\right)$, Myanmar $\left(\sim-37 \mathrm{Wm}^{-2}\right)$ and the Western Ghats $\left(\sim-31 \mathrm{Wm}^{-2}\right)$. Using RRTM and the cloud vertical model, the TOA flux and CRF over the negative NETCRF regions during the summer monsoon season was studied. Using the cloud vertical model as input, NETCRF for the three regions was estimated using RRTM. The NETCRF val-
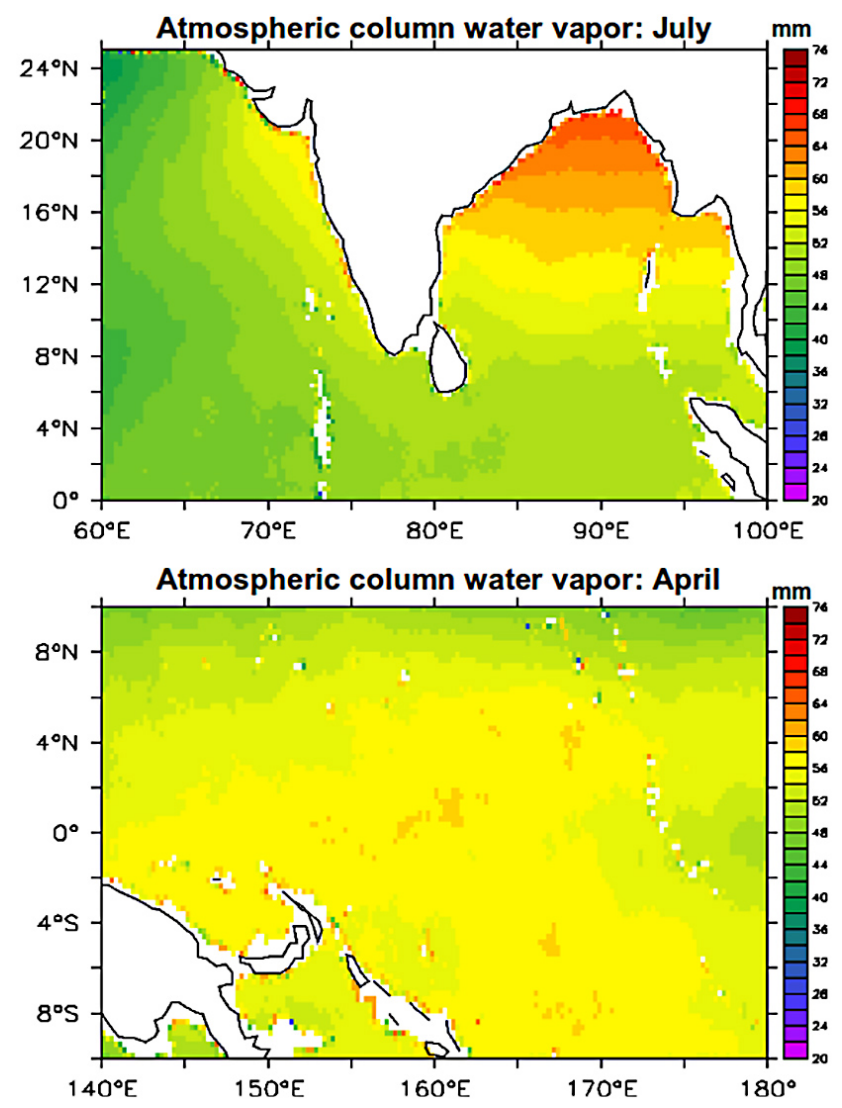

Figure 9. Regional variation in monthly mean atmospheric water vapor $(\mathrm{mm})$ from SSM/I over the Indian region (top panel) during the month of July and the western Pacific (bottom panel) during the month of April for the years 2002-2005.

ues calculated from RRTM simulations were found to agree well with CERES observations, while those from ISCCP-FD data showed large differences. The sensitivity of the negative NETCRF values to various cloud micro/macrophysical and environmental variables was tested using model simulations. The sensitivity of ice particle size to the NETCRF was evaluated by varying the ice particle radius (from 20 to $40 \mu \mathrm{m}$ ) in the parameterization of SSA, which produced a maximum variation of $\sim 10 \mathrm{Wm}^{-2}$ on the NETCRF values. The decrease in cloud particle size was found to increase the SWCRF with very little variation in LWCRF. However, variations in CRF due to changes in cloud particle size alone is not sufficient enough to cause the formation of negative NETCRF regimes observed over the Indian region.

Studies have shown that low-level cloud fraction has very little influence in controlling the NETCRF values over the three negative NETCRF regions. RRTM simulations of LWCRF employing the model atmosphere with varying PW values showed that atmospheric water vapor content significantly influences the NETCRF values observed over the region. The precipitable water amount is found to be higher $(>55 \mathrm{~mm}$ ) over the Bay of Bengal and Myanmar region 
compared to other locations over the Indian region during the monsoon season. Similarly, the clear-sky TOA LW flux over Bay of Bengal and Myanmar region was found to be significantly smaller $\left(\sim 276 \mathrm{Wm}^{-2}\right)$ during the summer monsoon season compared to winter months $\left(\sim 300 \mathrm{Wm}^{-2}\right)$. This increase in atmospheric water vapor associated with the convective activity over the Indian region during the monsoon season reduces the TOA LW clear-sky flux and LWCRF. Influence of water vapor loading is largest over the northern Bay of Bengal region close to the Myanmar coast where the total cloud amount is also largest. This indicates that the combined effect of a large amount of high-level clouds and increased atmospheric water vapor loading over the Indian region significantly influences the imbalance between LWCRF and SWCRF. Intercomparison between CRF values observed over the Bay of Bengal and the western Pacific also indicates the importance of atmospheric water vapor in controlling the magnitude of NETCRF values. Precipitable water vapor content over the northern Bay of Bengal region reaches as high as $\sim 70 \mathrm{~mm}$ during the monsoon months, while it hardly reaches $60 \mathrm{~mm}$ over the western Pacific. The damping of LWCRF caused by the increased atmospheric water vapor loading and the presence of a large amount of high clouds over the Indian region during the summer monsoon season creates an imbalance between SWCRF and LWCRF and is accountable for the observed negative NETCRF values over the region.

In future studies, more effort should be directed towards evaluating the relative role of clear-sky vs. total-sky water vapor burden in modulating the CRF. Using CERES EBAFderived TOA clear-sky measurements over the overcast regions can reduce the environmental difference in water vapor burden between clear- and total-sky environments to a certain extent (but by no means eliminate it completely). Since increase in atmospheric water vapor is well correlated with deep cloud cover over the convective regions, it is very difficult to ascertain the contribution of water vapor burden to clear-sky TOA LW flux. One way to solve such a problem using satellite observations could be to explore the water vapor vertical distributions (of clear-sky and total-sky environment) together with simultaneous radiation measurements, which is now possible by using the SAPHIR (water vapor) and SCARAB (radiation) instruments onboard the MeghaTropiques satellite (Desbois et al., 2007).

Acknowledgements. The TOA flux data used in the study were obtained from the NASA Langley Research Center EOSDIS Distributed Active Archive Center. The ISCCP-FD data were obtained from the International Satellite Cloud Climatology Project (http://isccp.giss.nasa.gov). SSM/I and SSMIS data are produced by Remote Sensing Systems and sponsored by the NASA Earth Science MEaSUREs Program and are available at http://www.remss.com. Technical and data support from the Climserv/LMD team is greatly appreciated. The authors thank Eli Mlawer and the Atmospheric and Environmental Research (AER) team for providing the RRTMG model (http://rtweb.aer.com/). B. V. Thampi acknowledges CNES, France, for providing the post-doc research fellowship. The authors acknowledge the support and help of colleagues at LMD/UPMC, France.

Edited by: J. Quaas

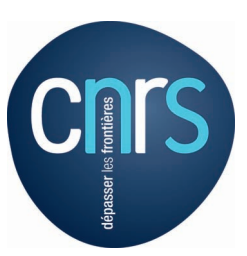

The publication of this article is financed by CNRS-INSU.

\section{References}

Balachandran, S. and Rajeevan, M.: Sensitivity of surface radiation budget to clouds over the Asian monsoon region, J. Earth Syst. Sci., 116, 159-169, 2007.

Barker, H. W., Stephens, G. L., Partain, P. T., Bergman, J. B., Bonnel, B., Campana, K., Clothiaux, E. E., Clough, S., Cusack, S., Delamere, J., Edwards, J., Evans, K. F., Fouquart, Y., Freidenreich, S., Galin, V., Hou, Y., Kato, S., Li, J., Mlawer, E., Morcrette, J.-J., O'Hirok, W., Räisänen, P., Ramaswamy, V., Ritter, B., Rozanov, E., Schlesinger, M., Shibata, K., Sporyshev, P., Sun, Z., Wendisch, M., Wood, N., and Yang, F.: Assessing 1D atmospheric solar radiative transfer models: Interpretation and handling of unresolved clouds, J. Climate, 16, 2676-2699, 2003.

Bergman, J. W. and Hendon, H. H.: Calculating Monthly Radiative Fluxes and Heating Rates from Monthly Cloud Observations, J. Atmos. Sci., 55, 3471-3492, 1998.

Bodas-Salcedo, A., Webb, M. J., Bony, S., Chepfer, H., Dufresne, J.-L., Klein, S. A., Zhang, Y., Marchand, R., Haynes, J. M., Pincus, R., and John, V. O.: COSP: satellite simulation software for model assessment, B. Am. Meteorol. Soc., 92, 1023-1043, 2011.

Cess, R. D., Zhang, M., Wielicki, B. A., Young, D. F., Zhou, X. L., and Nikitenko, Y.: The Influence of the 1998 El Niño upon Cloud-Radiative Forcing over the Pacific Warm Pool, J. Climate, 14, 2129-2137, 2001.

Chambon, P., Jobard, I., Roca, R., and Viltard, N.: An investigation of the error budget of tropical rainfall accumulation derived from merged passive microwave and infrared satellite measurements, Q. J. Roy. Meteor. Soc., 139, 879-893, doi:10.1002/qj.1907, 2013.

Charlock, T. P. and Ramanathan, V.: The albedo field and cloud radiative forcing produced by a general circulation model with internally generated cloud optics, J. Atmos. Sci., 42, 1408-1429, 1985.

Chou, M.-D., Suarez, M. J., Ho, C-H., Yan, M. M.-H., and Lee, K.-T.: Parameterizations for cloud overlapping and shortwave single-scattering properties for use in general circulation and cloud ensemble models, J. Climate, 11, 202-214, 1998.

Clough, S. A., Shephard, M. W., Mlawer, E. J., Delamere, J. S., Iacono, M. J., Cady-Pereira, K., Boukabara, S., and Brown, P. D.: Atmospheric radiative transfer modeling: a summary of the AER codes, J. Quant. Spectrosc. Ra., 91, 233-244, 2005.

Cole, J., Barker, H. W., Loeb, N. G., and von Salzen, K.: Asessing simulated clouds and radiative fluxes using properties of clouds 
whose tops are exposed to space, J. Climate, 24, 2715-2727, 2011.

Collins, W. D.: Parameterization of generalized cloud overlap for radiative calculations in general circulation models, J. Atmos. Sci., 58, 3224-3242, 2001.

Desbois, M., Capderou, M., Eymard, L., Roca, R., Viltard, N., Viollier, M., and Karouche, N.: Megha- Tropiques: un satellite hydrométéorologique francoindien, La meteorologie, 53, 19-27, 2007.

Dessler, A. E. and Yang, P.: The distribution of tropical thin cirrus clouds inferred from Terra MODIS data, J. Climate, 16, 12411247, 2003.

Devasthale, A. and Fueglistaler, S.: A climatological perspective of deep convection penetrating the TTL during the Indian summer monsoon from the AVHRR and MODIS instruments, Atmos. Chem. Phys., 10, 4573-4582, doi:10.5194/acp-10-45732010, 2010.

Ellingson, R. G. and Fouquart, Y. : The intercomparison of radiation codes in climate models: An overview, J. Geophys. Res., 96, 8925-8927, 1991.

Ellingson, R. G. and Wiscombe, W. J.: The Spectral Radiance Experiment (SPECTRE): Project Description and Sample Results. B. Am. Meteorol. Soc., 77, 1967-1985, 1996.

Evans, J. S., Cooper, D. W., and Kinney, P.: On the propagation of error in air pollution measurements, Environ. Monit. Assess., 4, 139-153, 1984.

Fouquart, Y.: Radiation in boundary layer clouds, in: Report of the JSC/ CAS Workshop on Modelling of Cloud-Topped Boundary Layer, Fort Collins, Colorado, USA, 22-26 April, Appendix D, 40 pp., 1985.

Fouquart, Y. and Bonnel, B.: Computations of solar heating of the earth's atmosphere: A new parameterization, Beitr. Phys. Atmos., 53, 35-62, 1980.

$\mathrm{Fu}, \mathrm{Q} .:$ An accurate parameterization of the solar radiative properties of cirrus clouds for climate models, J. Climate, 9, 20582082, 1996.

Futyan, J. M., Russell, J. E., and Harries, J. E.: Cloud radiative forcing in Pacific, African, and Atlantic tropical convective regions, J. Climate, 17, 3192-3202, 2004.

Geleyn, J.-F. and Hollingsworth, A.: An economical analytical method for the computation of the interaction between scattering and line absorption of radiation, Beitr. Phys. Atmos., 52, 1-16, 1979.

Hahn, C. J., Rossow, W. B., and Warren, S. G.: ISCCP cloud properties associated with standard cloud types identified in individual surface observations, J. Climate, 14, 11-28, 2001.

Harrison, E. F., Minnis, P., Barkstrom, B. R., Ramanathan, V., Cess, R. D., and Gibson, G. G.: Seasonal variation of cloud radiative forcing derived from the Earth Radiation Budget Experiment, J. Geophys. Res., 95, 18687-18703, 1990.

Hartmann, D. L., Moy, L. A., and Fu, Q.: Tropical convection and the energy balance at the top of the atmosphere, J. Climate, 14, 4495-4511, 2001.

Hu, Y. X. and Stamnes, K.: An accurate parameterization of the radiative properties of water clouds suitable for use in climate models, J. Climate, 6, 728-742, 1993.

Iacono, M. J., Mlawer, E. J., Clough, S. A., and Morcrette, J.-J.: Impact of an improved longwave radiation model, RRTM, on the energy budget and thermodynamic properties of the NCAR com- munity climate model, CCM3, J. Geophys. Res., 105, 1487314890, doi:10.1029/2000JD900091, 2000.

Jensen, E. J., Kinne, S., and Toon, O. B.: Tropical cirrus cloud radiative forcing: Sensitivity studies. Geophys. Res. Lett., 21, 2023 2026, 1994.

Key, J. R. and Schweiger, A. J.: Tools for atmospheric radiative transfer: Streamer and FluxNet, Computat. Geosci., 24, 443-451, doi:10.1016/S0098-3004(97)00130-1, 1998.

Key, J. R., Yang, P., Baum, B. A., and Nasiri, S. L.: Parameterization of shortwave ice cloud optical properties for various particle habits, J. Geophys. Res., 107, AAC 7-1-AAC 7-10, doi:10.1029/2001JD000742, 2002.

Kiehl, J. T.: On the observed near cancellation between longwave and shortwave cloud forcing in tropical regions, J. Climate, 7, 559-565, 1994.

Kiehl, J. T. and Ramanathan, V.: Comparison of cloud forcing derived from Earth Radiation Budget Experiment with that simulated by the NCAR Community climate Model, J. Geophys. Res., 95, 1679-1698, 1990.

Klein, S. A. and Jakob, C.: Validation and sensitivities of frontal clouds simulated by the ECMWF model, Mon. Weather Rev., 127, 2514-2531, 1999.

Liou, K.-N.: Influence of cirrus clouds on weather and climate processes: A global perspective, Mon. Weather Rev., 114, 11671199, 1986.

Liou, K. N. and Ou, S. C.: The role of cloud microphysical processes in climate: an assessment from a one-dimensional perspective, J. Geophys. Res., 94, 8599-8607, 1989.

Lo, E.: Gaussian error propagation applied to ecological data: postice-storm-downed woody biomass, Ecol. Monogr., 75, 451-466, 2005.

Loeb, N. G., Kato, S., Loukachine, K., and Manalo-Smith, N.: Angular distribution models for top-of-atmosphere radiative flux estimation from the Clouds and the Earth's Radiant Energy System instrument on the Terra satellite, Part I: Methodology. J. Atmos. Ocean. Tech., 22, 338-351, 2005.

Loeb, N. G., Wielicki, B. A., Doelling, D. R., Smith, G. L., Keyes, D. F., Kato, S., Manalo-Smith, N., and Wong, T.: Toward optimal closure of the earth's top-of-atmosphere radiation budget, J. Climate, 22, 748-766, 2009a.

Loeb, N. G., Wielicki, B. A., Wong, T., and Parker, P. A.: Impact of data gaps on satellite broadband radiation records, J. Geophys. Res., 114, D11109, doi:10.1029/2008JD011183, 2009b.

Meenu, S., Rajeev, K., Parameswaran, K., and Suresh Raju, C.: Characteristics of the double intertropical convergence zone over the tropical Indian Ocean, J. Geophys. Res., 112, D11106, doi:10.1029/2006JD007950, 2007.

Meenu, S., Rajeev, K., Parameswaran, K., and Nair, A. K. M.: Regional distribution of deep clouds and cloud top altitudes over the Indian subcontinent and the surrounding oceans, J. Geophys. Res., 115, D05205, doi:10.1029/2009JD011802, 2010.

Menzel, W. P., Frey, R. A., Zhang, H., Wylie, D. P., Moeller, C. C., Holz, R. E., Maddux, B., Baum, B. A., Strabala, K. I., and Gumley, L. E.: MODIS global cloud top pressure and amount estimation: Algorithm description and results, J. Appl. Meteorol. Clim., 47, 1175-1198, doi:10.1175/2007JAMC1705.1, 2008.

Mlawer, E. J., Taubman, S. J., Brown, P. D., Iacono, M. J., and Clough, S.A.: RRTM, a validated correlated-k model for the longwave, J. Geophys. Res., 102, 16663-16682, 1997. 
Morcrette, J.-J., Barker, H. W., Cole, J., Iacono, M., and Pincus, R.: Impact of a new radiation package, McRad, in the ECMWF integrated forecasting system, Mon. Weather Rev., 136, 47734798, 2008.

Pai, D. S. and Rajeevan, M.: Clouds and cloud radiative forcing over tropical Indian ocean and their relationship with sea surface temperature, Curr. Sci. India, 75, 372-381, 1998.

Patil, S. D. and Yadav, R. K.: Large-scale changes in the cloud radiative forcing over the Indian region, Atmos. Environ., 39, 46094618, 2005.

Pavlakis, K. G., Hatzianastassiou, N., Matsoukas, C., Fotiadi, A., and Vardavas, I.: ENSO surface shortwave radiation forcing over the tropical Pacific, Atmos. Chem. Phys., 8, 5565-5577, doi:10.5194/acp-8-5565-2008, 2008.

Pincus, R., Barker, H. W., and Morcrette, J.-J.: A fast, flexible, approximate technique for computing radiative transfer in inhomogeneous cloud fields, J. Geophys. Res., 108, 4376, doi:10.1029/2002JD003322, 2003.

Platt, C. M. R.: A parameterization of the visible extinction coefficient of ice clouds in terms of the ice/water content, J. Atmos. Sci., 54, 2083-2098, 1997.

Räisänen, P.: Parameterization of water and ice cloud near-infrared single-scattering co-albedo in broadband radiation schemes, J. Atmos. Sci., 56, 626-641, 1999.

Rajeevan, M. and Srinivasan, J.: Net cloud radiative forcing at the top of the atmosphere in the Asian monsoon region, J. Climate, 13, 650-657, 2000.

Ramanathan, V., Cess, R. D., Harrison, E. F., Minnis, P., Barkstrom, B. R., Ahmad, E., and Hartmann, D.: Cloud-radiative forcing and climate: Results from the Earth Radiation Budget Experiment, Science, 243, 57-63, 1989.

Remer, L. A., Kaufman, Y. J., Tanré, D., Mattoo, S., Chu, D. A., Martins, J. V., Li, R.-R.., Ichoku, C., Levy, R. C., Kleidman, R. G., Eck, T. F., Vermote, E., and Holben, B. N.: The MODIS Aerosol Algorithm, Products, and Validation, J. Atmos. Sci., 62, 947-973, 2005.

Roca, R., Louvet, S., Picon, L., and Desbois, M.: A study of convective systems, water vapor and top of the atmosphere cloud radiative forcing over the Indian Ocean using INSAT-1B and ERBE data, Meteorol. Atmos. Phys., 90, 49-65, 2004.

Rossow, W. B. and Zhang, Y. C.: Calculation of surface and top of atmosphere radiative fluxes from physical quantities based on ISCCP datasets. 2. Validation and first results, J. Geophys. Res, 100, 1167-1197, 1995.

Rossow, W. B., Zhang, Y., and Wang, J.: A statistical model of cloud vertical structure based on reconciling cloud layer amounts inferred from satellites and radiosonde humidity profiles, J. Climate, 18, 3587-3605, 2005.

Schmidt, E. O., Arduini, R. F., Wielicki, B. A., Stone, R. S., and Tsay, S.-C.: Considerations for modeling thin cirrus effects via brightness temperature differences, J. Appl. Meteorol., 34, 447459, 1995.

Slingo, A.: A GCM parameterization for the shortwave radiative properties of water clouds, J. Atmos. Sci., 46, 1419-1427, 1989.

Slingo, A. and Schrecker, H. M.: On the shortwave radiative properties of stratiform water clouds, Q. J. Roy. Meteor. Soc., 108, 407-426, 1982.

Smith, G. L., Mlynczak, P. E., and Potter, G. L.: A technique using principal component analysis to compare seasonal cycles of
Earth radiation from CERES and model computations, J. Geophys. Res., 117, D09116, doi:10.1029/2011JD017343, 2012.

Sohn, B.-J. and Schmetz, J.: Water vapor-induced OLR variations associated with high cloud changes over the tropics: A study from Meteosat-5 observations, J. Climate, 17, 1987-1996, 2004.

Sohn, B.-J. and Bennartz, R.: Contribution of water vapor to observational estimates of longwave cloud radiative forcing, J. Geophys. Res., 113, D20107, doi:10.1029/2008JD010053, 2008.

Sohn, B.-J., Schmetz, J., Stuhlmann, R., and Lee, J. -Y.: Dry bias in satellite-derived clear-sky water vapor and its contribution to longwave cloud radiative forcing, J. Climate, 19, 5570-5580, 2006.

Stephens, G. L., Tsay, S. C., Stackhouse Jr., P. W., and Platau, P. J.: The relevance of the microphysical and radiative properties of cirrus clouds to climate and climate feedback, J. Atmos. Sci., 47, 1742-1753, 1990 .

Stephens, G. L., Wood, N. B., and Gabriel, P. M.: An Assessment of the parameterization of subgrid-scale cloud Effects on radiative transfer. Part I: Vertical overlap, J. Atmos. Sci., 61, 715-732, 2004.

Sun, Z. and Shine, K. P.: Studies of the radiative properties of ice and mixed-phase clouds, Q. J. Roy. Meteor. Soc., 120, 111-137, 1994.

Tang, X. and Chen, B: Cloud types associated with the Asian summer monsoons as determined from MODIS/TERRA measurements and a comparison with surface observations, Geophys. Res. Lett., 33, L07814, doi:10.1029/2006GL026004, 2006.

Taylor, J. R.: An introduction to error analysis, University Science Books, Mill Valley, California, USA, 1982.

Tian, L. and Curry, J. A.: Cloud overlap statistics, J. Geophys. Res., 94, 9925-9935, 1989.

Warren, S. G., Hahn, C. J., and London, J.: Simultaneous occurrence of different cloud types, J. Clim. Appl. Meteorol., 24, 658-667, 1985.

Weare, B. C.: Combined satellite- and surface-based observations of clouds, J. Climate, 12, 897-913, 1999.

Webb, M., Senior, C., Bony, S., and Morcrette, J.-J.: Combining ERBE and ISCCP data to assess clouds in the Hadley Centre, ECMWF and LMD atmospheric climate models, Clim. Dynam., 17, 905-922, 2001.

Wentz, F. J.: A well-calibrated ocean algorithm for SSM/I, J. Geophys. Res., 102, 8703-8718, 1997.

Wielicki, B. A., Cess, R. D., King, M. D., Randall, D. A., and Harrison, E. F.: Mission to Planet Earth: Role of clouds and radiation in climate, B. Am. Meteorol. Soc., 76, 2125-2153, 1995.

Wyser, K. and Yang, P.: Average ice crystal size and bulk shortwave single-scattering properties of cirrus clouds, Atmos. Res., 49, 315-335, 1998.

Young, D. F., Minnis, P., Doelling, D. R., Gibson, G. G., and Wong, T.: Temporal interpolation methods for the Clouds and the Earth's Radiant Energy System (CERES) Experiment, J. Appl. Meteorol., 37, 572-590, 1998.

Zhang, M. H., Lin, W. Y., Klein, S. A., Bacmeister, J. T., Bony, S., Cederwall, R. T., Del Genio, A. D., Hack, J. J., Loeb, N. G., Lohmann, U., Minnis, P., Musat, I., Pincus, R., Stier, P., Suarez, M. J., Webb, M. J., Wu, J. B., Xie, S. C., and Yao, M.-S.: Comparing clouds and their seasonal variations in 10 atmospheric general circulation models with satellite measurements, J. Geophys. Res., 110, D15S02, doi:10.1029/2004JD005021, 2005. 
Zhang, Y., Macke, A., and Albers, F.: Effect of crystal size spectrum and crystal shape on stratiform cirrus radiative forcing, Atmos. Res., 52, 59-75, 1999.

Zhang, Y. C., Rossow, W. B., and Lacis, A. A.: Calculation of surface and top of atmosphere radiative fluxes from physical quantities based on ISCCP datasets. 1. Method and sensitivity to input data uncertainties, J. Geophys. Res, 100, 1149-1165, 1995.
Zhang, Y.-C., Rossow, W. B., Lacis, A. A., Oinas, V., and Mishchenko, M. I.: Calculation of radiative fluxes from the surface to top of atmosphere based on ISCCP and other global datasets: Refinements of the radiative transfer model and the input data, J. Geophys. Res., 109, D19105, doi:10.1029/2003JD004457, 2004.

Zuluaga, M. D., Hoyos, C. D., and Webster, P. J.: Spatial and temporal distribution of latent heating in the south Asian monsoon region, J. Climate, 23, 2010-2029, doi:10.1175/2009JCLI3026.1, 2010 . 